\title{
Void evolution in tungsten and tungsten-5wt.\% tantalum under in-situ proton irradiation at 800 and $1000{ }^{\circ} \mathrm{C}$
}

DOI:

10.1016/j.jnucmat.2019.07.030

\section{Document Version}

Accepted author manuscript

Link to publication record in Manchester Research Explorer

\section{Citation for published version (APA):}

Ipatova, I., Harrison, R., Donnelly, S. E., Rushton, M. J. D., Middleburgh, S. C., \& Jimenez-Melero, E. (2019). Void evolution in tungsten and tungsten-5wt.\% tantalum under in-situ proton irradiation at 800 and $1000{ }^{\circ} \mathrm{C}$. Journal of Nuclear Materials, 526, [151730]. https://doi.org/10.1016/j.jnucmat.2019.07.030

\section{Published in:}

Journal of Nuclear Materials

\section{Citing this paper}

Please note that where the full-text provided on Manchester Research Explorer is the Author Accepted Manuscript or Proof version this may differ from the final Published version. If citing, it is advised that you check and use the publisher's definitive version.

\section{General rights}

Copyright and moral rights for the publications made accessible in the Research Explorer are retained by the authors and/or other copyright owners and it is a condition of accessing publications that users recognise and abide by the legal requirements associated with these rights.

\section{Takedown policy}

If you believe that this document breaches copyright please refer to the University of Manchester's Takedown Procedures [http://man.ac.uk/04Y6Bo] or contact uml.scholarlycommunications@manchester.ac.uk providing relevant details, so we can investigate your claim.

\section{OPEN ACCESS}




\section{Void evolution in tungsten and tungsten-5wt.\% tantalum}

\section{under in-situ proton irradiation at 800 and $1000{ }^{\circ} \mathrm{C}$}

I. Ipatova ${ }^{a^{*}}$, R.W. Harrison ${ }^{b, c}$, S. E. Donnelly ${ }^{b}$, M.J.D. Rushton ${ }^{a}$, S.C. Middleburgh ${ }^{\mathrm{a}}$,

E. Jimenez-Metere ${ }^{\mathrm{d}}$

${ }^{a}$ Nuclear Futures Institute, Bangor University, Dean Street,

Bangor Gwynedd, LL57 1 UT, UK

${ }^{b}$ School of Computing and Engineering, University of Huddersfield,

Huddersfield, HD1 3DH, UK

'School of Mechanical, Aerospace and Civil Engineering, Materials Performance Centre,

The University of Manchester, Manchester M13 9PL, UK

${ }^{d}$ Materials Performance Centre, School of Materials, The University of Manchester,

Manchester M13 9PL, UK

Corresponding author $(*)$ :

Nuclear Futures

Bangor University

Dean Street

Bangor, Gwynedd

LL57 1UT

United Kingdom

Tel.: +44 7849290480

Email: 1.ipatova@bangor.ac.uk 


\begin{abstract}
We have probed void evolution in polycrystalline $\mathrm{W}$ and $\mathrm{W}-5 \mathrm{wt} . \%$ Ta material at 800 and $1000{ }^{\circ} \mathrm{C}$, by transmission electron microscopy during in-situ irradiation with a $40 \mathrm{keV}$ proton beam. The presence of radiation-induced dislocation loops was not observed prior to void formation at those elevated temperatures. The damaged $\mathrm{W}$ microstructure was characterised by the presence of a population of randomly distributed voids, whose number density reduces when the irradiation temperature increases. Soft impingement of voids becomes noticeable at damage levels $\geq 0.2 \mathrm{dpa}$. In contrast, the excess of free vacancies in the W-5wt.\%Ta material irradiated at $800^{\circ} \mathrm{C}$ only leads to the formation of visible voids in this TEM study $(\geq 2 \mathrm{~nm})$ after post-irradiation annealing of the sample at $1000{ }^{\circ} \mathrm{C}$. Solute Ta atoms also cause a significant increase in the number density of voids when comparing the microstructure of both materials irradiated at $1000^{\circ} \mathrm{C}$, and a gradual progression towards saturation in average void size at $\geq 0.2 \mathrm{dpa}$. Moreover, we have detected a progressive transition from a spherical to a faceted shape in a number of voids present in both materials at damage levels $\geq 0.3$ dpa.
\end{abstract}

Keywords: W/W-5Ta, materials for fusion, radiation damage, faceted voids, transmission electron microscopy 


\section{Introduction}

Tungsten has traditionally stood out within the refractory metal group as the prime plasma-facing candidate for armour components of magnetically-confined tokamak fusion reactors. Tungsten may potentially be used in the future, for the underlying cooling structures as well, if taking advantage of the incipient additive manufacturing technologies for optimised geometries $[1,2]$. The attractiveness of tungsten is due to its high melting point $\left(T_{m}=3422^{\circ} \mathrm{C}\right)$ and its resistance to sputtering from accidental plasma-material interactions, together with suitable thermal conductivity, shock resistance and high-temperature strength [3-5]. Tungsten was used as a $\sim 25 \mu \mathrm{m}$-thick coating on the carbon fibre composite divertor tiles during the second JET ITER-like wall campaign of 2013-2014 [6, 7]. In ITER, tungsten tiles will also be placed on the top section of the arched stainless-steel plasma confinement construction. During regular operation modes, the full-tungsten armour will experience heat loads of $\sim 6.5-10 \mathrm{MW} / \mathrm{m}^{2}$, attaining values close to $20 \mathrm{MW} / \mathrm{m}^{2}$ during short transient events. Additionally, a $14 \mathrm{MeV}$ neutron-induced damage level of $\sim 0.1$ dpa is predicted to be accumulated by the tungsten monoblocks after the 4-year ITER nuclear phase prior to the cassette replacement of the first divertor, and $\sim 0.5 \mathrm{dpa}$ for permanent divertor components during ITER's end-of-life operation [8]. Furthermore, current blanket designs for the future fusion demonstration power plant (DEMO) are based on a first wall in which the tungsten armour is joined to a structure made of Reduced Activation Ferritic Martensitic (RAFM) steel [9]. Water-cooled DEMO divertor designs under consideration are also based on ITER-like tungsten monoblocks [10].

The recommended low-temperature limit for safe operation of body-centred cubic (bcc) metals such as tungsten is dictated by radiation-induced hardening and embrittlement, occurring even for doses $\leq 1 \mathrm{dpa}$ [11]. Unfortunately, tungsten is inherently brittle at low temperatures, being characterized by a ductile-to-brittle transition temperature (DBTT) in the 
range of $\sim 200-400{ }^{\circ} \mathrm{C}$. Both the value of the DBTT and of the low-temperature fracture toughness depend on the material processing route [12], and consequently on the microstructure and its anisotropy [13-15]. Additionally, exposure to neutron bombardment can shift the DBTT up to $\sim 800-1000{ }^{\circ} \mathrm{C}$ and exacerbates the propensity for brittle failure at lower temperatures $[11,16,17]$. Tungsten irradiated with thermal or mixed neutrons to a damage level of $<1$ dpa and at temperatures below the vacancy-mediated stage III recovery, i.e. below $\sim 0.15 T_{m}$ depending on neutron energy spectrum and fluence, presents primarily a population of $a_{0} / 2<111>$ interstitial dislocation loops [18-20]. At higher temperatures, those loops tend to migrate and form larger interstitial-type structures [19]. Relatively high fast/mixed energy neutron fluences, at temperatures as low as $70{ }^{\circ} \mathrm{C}$, also induce the occurrence of diffuse vacancy clusters and voids [21, 22]. Additionally, an increase in damage level to $>1$ dpa leads to the formation of nano-scale precipitates, involving Re and Os atoms resulting from transmutation [20]. These dominate radiation-induced hardening at relatively high damage levels [23]. Radiation-induced dislocation loops and voids act as effective trapping sites for mobile species and promote the nucleation of W-Re-Os precipitates [24]. In recent years ion irradiation experiments, especially those coupled with in-situ transmission electron microscopy, have shed complementary light on radiationinduced lattice defect evolution [25]. 1-D loop hopping has been observed in-situ in the temperature range of $300-700{ }^{\circ} \mathrm{C}$, together with loop growth primarily by absorption $[26,27]$.

A promising strategy to make $\mathrm{W}$ more ductile is to introduce high-temperature elements (e.g. Ta, V, Ti, Mo, Re) either in solid solution or as short fibres in the $\mathrm{W}$ matrix [28-30]. In the former case, the predicted W-Ta phase diagram confirms that Ta remains in solid solution at concentrations $<10 \mathrm{wt} . \% \mathrm{Ta}$, whereas there is a tendency to form either B2 (CsCl-type) or $\mathrm{DO}_{3}\left(\mathrm{Fe}_{3} \mathrm{Al}\right.$-type) ordered phases depending on temperature up to $727^{\circ} \mathrm{C}$ and on Ta content $>10 \mathrm{wt} . \%$ [31]. Self-ion irradiation of $\mathrm{W}-5 \mathrm{Ta}(\mathrm{W}-5 \mathrm{wt} \% \mathrm{Ta})$ at $300-500{ }^{\circ} \mathrm{C}$ up to 
33 dpa does not induce significant Ta clustering. However, the presence of 5wt.\%Ta hinders the formation of radiation-induced Re-rich clusters, and also causes a higher dislocation loop density as compared to irradiated $\mathrm{W}$ under equivalent experimental conditions, but with a smaller average loop size [32-34]. Moreover, the loop size in W-5Ta proton-irradiated at $350{ }^{\circ} \mathrm{C}$ saturates at only $0.3 \mathrm{dpa}$, whereas the loop length in $\mathrm{W}$ continues to increase with damage level, giving rise to the formation of dislocation strings [35]. Recently systematic DFT simulations of tungsten self-interstitial atom clusters have revealed that Ta strongly repels interstitial clusters, especially when Ta is located on the periphery of the cluster [36].

In contrast, the upper temperature limit of structural materials such as $\mathrm{W}$ and its alloys is controlled by thermal creep, high-temperature helium embrittlement and void swelling [11]. In this respect, a significant number of annealing experiments have been reported in tungsten samples that had previously been irradiated at different low temperatures and damage levels, and with varying neutron energy spectra [20, 37-40], proton [41] or self-ion $[27,42]$ beams. Stage III recovery $\left(\geq 0.15 T_{m}\right)$ is characterised by vacancy migration, whereas in stage IV $\left(\geq 0.22 T_{m}\right)$ there is migration of vacancy clusters and vacancy-impurity complexes that become unstable and start emitting vacancies at $\geq 0.31 T_{m}$ (stage $\mathrm{V}$ ). The interstitial-type $a_{0} / 2<111>$ dislocation loops emit self-interstitial atoms at temperatures $>500{ }^{\circ} \mathrm{C}$. The vacancy excess in the matrix evolves into vacancy-type $a_{0} / 2<111>$ dislocation loops at $600-900{ }^{\circ} \mathrm{C}$ and into voids at $>1000{ }^{\circ} \mathrm{C}$ [41]. Energy calculations of mesoscopic defect configurations in $\mathrm{W}$ using many-body interatomic potentials revealed that spherical voids are the most energetically favourable configuration, and vacancy-type loops therefore represent metastable configurations that would evolve into a void structure [43]. In neutron irradiated $\mathrm{W}$, voids are already visible at $\sim 430{ }^{\circ} \mathrm{C}$, with a maximum in void swelling at $\sim 0.31 \mathrm{Tm}=$ $1060{ }^{\circ} \mathrm{C}[20,44]$. Voids larger than $10 \mathrm{~nm}$ were faceted, with facet planes of $\{211\}$ and $\{110\}[20]$. A void lattice structure, characterised by a void lattice parameter of $195 \AA$ and a 
lattice parameter to average void size ratio of about six, was observed in neutron irradiated W at $550{ }^{\circ} \mathrm{C}$ to a neutron fluence of $1 \times 10^{22}$ neutrons $/ \mathrm{cm}^{2}$ [45]. Moreover, a very low density of interstitial loops was detected in the temperature range of $500-800{ }^{\circ} \mathrm{C}$ up to 2.2 dpa [23]. Despite the wealth of reports about low-temperature radiation damage structures in $\mathrm{W}$ and alloys, their thermal stability post irradiation, and the formation of radiation-induced void structures in neutron irradiated $\mathrm{W}$, the formation of defect structures in $\mathrm{W}$ at elevated temperatures and the role of Ta remain largely unexplored. In this study, we focus on in-situ monitoring of radiation-induced void evolution in $\mathrm{W}$ and $\mathrm{W}-5 \mathrm{Ta}$ at damage levels $\leq 0.4 \mathrm{dpa}$ and at two target temperatures: $800{ }^{\circ} \mathrm{C}$ and $1000{ }^{\circ} \mathrm{C}$.

\section{Experimental}

The initial W (99.95\%) was provided by Goodfellow Cambridge Ltd. in the form of $1 \mathrm{~mm}$ thick sheet. The as-received $\mathrm{W}$ material was annealed in vacuum at $1400{ }^{\circ} \mathrm{C}$ for $2 \mathrm{~h}$ for recrystallization. The W-5Ta material was produced by powder metallurgy and provided by Plansee AG. The material was double forged and then annealed at $1600{ }^{\circ} \mathrm{C}$ for $1 \mathrm{~h} \mathrm{[46].} \mathrm{After}$ delivery, the material was annealed for $1 \mathrm{~h}$ at $1000{ }^{\circ} \mathrm{C}$ for degassing [47]. Afterwards, smaller samples of $2 \times 2 \mathrm{~cm}^{2}$ were cut and annealed at $1400{ }^{\circ} \mathrm{C}$ for $2 \mathrm{~h}$ to remove the defects from machining. TEM discs of both materials were prepared by mechanical pre-thinning, using $\mathrm{SiC}$ abrasive papers with successively smaller grit size (from grit 220 up to 4000). Then the procedure was followed by electropolishing at a temperature of $\sim-5{ }^{\circ} \mathrm{C}$ using a Struers Tenupol-5 unit and an electrolyte comprising an aqueous solution of $0.5 \mathrm{wt} \% \mathrm{Na}_{2} \mathrm{~S}$ for electropolishing $\mathrm{W}$, or a mixture of $15 \mathrm{vol} \%$ sulphuric acid $(95 \%)$ and $85 \mathrm{vol} \%$ methanol in the case of W-5Ta. The grain structure of both materials is presented in [35]. The average grain size was $2.3 \pm 0.7 \mathrm{~mm}(\mathrm{~W}-5 \mathrm{Ta})$ and $3.9 \pm 0.8 \mathrm{~mm}(\mathrm{~W})$.

In-situ irradiation experiments were performed on the MIAMI-II TEM/ion accelerator system located at the University of Huddersfield [48]. The in-situ irradiation facility 
comprises a Hitachi H-9500 transmission electron microscope (TEM) with a maximum operating voltage of $300 \mathrm{kV}$, coupled to a $350 \mathrm{kV}$ National Electrostatics Corporation ion accelerator incorporating a Danfysik 921A ion source capable of providing ions of most species up to $\mathrm{Au}$. The ion beam is incident on the sample at an angle of $18.7^{\circ}$ to the electron beam. A double-tilt heating holder (Gatan Model 652) was used to reach the target temperature, i.e. 800 or $1000^{\circ} \mathrm{C}$. This heating holder uses current flow through a Ta furnace surrounding the sample, measuring temperature via a thermocouple attached to the furnace. Proton irradiation started after temperature stabilization. The specimen is held in place using a Hexring ${ }^{\circledR}$ specimen clamping mechanism to ensure good thermal contact between the specimen and the furnace. Heat transfer calculations for the $40 \mathrm{keV}$ proton beam of 0.2 nanoAmps of current and with a flux of $6-8 * 10^{13}$ ions $/ \mathrm{cm}^{2} / \mathrm{s}$, and taking into account the sample thickness and heat capacity, revealed changes in sample temperature due to the proton beam of $<1^{\circ} \mathrm{C}$. The damage level for the sample irradiated in-situ with $40 \mathrm{keV}$ protons was estimated as the average value in the foil thickness of $\sim 100-110 \mathrm{~nm}$, as determined by Convergent Electron Beam Diffraction (CBED) prior to the experiment for consistency and comparison amongst samples under equivalent fluence and/or temperature values. These foils were irradiated with $40 \mathrm{keV}$ protons at those two temperatures and at increasing damage levels up to $0.4 \mathrm{dpa}$ for each material. The W-5Ta sample that had been irradiated, step-wise, up to $0.3 \mathrm{dpa}$ at $800{ }^{\circ} \mathrm{C}$ was subsequently annealed at $1000{ }^{\circ} \mathrm{C}$ for $15 \mathrm{~min}$. The main parameters for each irradiation experiment are collected in Table 1. The simulated damage profile was calculated using the SRIM software with the quick Kinchin-Pease approach [49, 50], using an average displacement energy of $90 \mathrm{eV}$ [51] and default values for other software settings. The total current deposited on the sample is given in Table 1, and it was predicted that $97 \%$ of the incoming protons would have been transmitted through the foil. The Bragg peak for $40 \mathrm{keV}$ protons in $\mathrm{W}$ occurs at $130 \mathrm{~nm}$ [35]. Micrographs were recorded 
along the zone axes $<100>$ and $<111>$ during the step-wise increase in damage level. Images of the same regions of interest were taken under different two-beam diffraction conditions, by tilting the sample using the double-tilt holder, in order to check the potential presence of radiation-induced loops along the zone axes. The "out-of-focus" Fresnel imaging technique was used for bright-field void detection (see Fig. S1 and Fig. S2). Due to the inner potential difference between the void and the surrounding matrix, voids appear as white dots surrounded by black Fresnel fringes when recorded in an under-focused condition, and as dark dots with bright fringes in an over-focused condition. At each new damage level, a through-focal series of micrographs was taken with a defocus value $\Delta f \leq 1 \mu \mathrm{m}$ to feature voids of $\geq 1 \mathrm{~nm}$ in diameter [52]. The average void size was determined using the micrographs taken in over-focus condition and all voids visible in TEM were $\geq 2 \mathrm{~nm}$.

\section{Results}

The occurrence and evolution of radiation-induced voids at the two selected temperatures are displayed in Fig. 1 and 2 for $\mathrm{W}$ and $\mathrm{W}-5 \mathrm{Ta}$, respectively. The main microstructural parameters characterizing the void structure are collected in Table 2. In both materials and at both irradiation temperatures, the damaged structure was characterised by the formation of voids that changed in number, size and morphology with increasing damage level. The presence of radiation-induced dislocation loops was not detected at any of those irradiation temperatures. The number density of voids in the $\mathrm{W}$ sample irradiated at $800^{\circ} \mathrm{C}$ increases continuously up to the maximum damage level of $0.4 \mathrm{dpa}$, with a faster increase up to $0.2 \mathrm{dpa}$, and a somewhat lower rate of change with damage level beyond $0.2 \mathrm{dpa}$. This transition coincides with a higher increase in the average void size with damage level at $\geq 0.2$ dpa (Fig. 4). At the irradiation temperature of $1000{ }^{\circ} \mathrm{C}, \mathrm{W}$ shows a similar trend in void evolution with damage level, but with a significantly lower density and a larger average void size. At $0.4 \mathrm{dpa}$, the void densities are $(52.5 \pm 5.3) \times 10^{21} \mathrm{~m}^{-3}\left(800{ }^{\circ} \mathrm{C}\right)$ and 
$(5.6 \pm 0.6) \times 10^{21} \mathrm{~m}^{-3}\left(1000{ }^{\circ} \mathrm{C}\right)$, whereas the average void sizes are $5.7 \pm 0.6 \mathrm{~nm}\left(800{ }^{\circ} \mathrm{C}\right)$ and $7.1 \pm 1.3 \mathrm{~nm}\left(1000^{\circ} \mathrm{C}\right)$. In contrast, radiation-induced voids were not detected in the $\mathrm{W}-5$ Ta sample irradiated at $800{ }^{\circ} \mathrm{C}$ up to $0.3 \mathrm{dpa}$. Interestingly, voids are visible when the same sample is post-irradiation annealed at $1000^{\circ} \mathrm{C}$, with a void density of $4.9 \pm 1.4 \times 10^{21}$ $\mathrm{m}^{-3}$ and an average size of $4.9 \pm 1.4 \mathrm{~nm}$. This results from void agglomeration by a thermally activated process. Furthermore, the presence of $5 \mathrm{wt} . \%$ Ta causes a significant increase in void density at $1000{ }^{\circ} \mathrm{C}$ as compared to the $\mathrm{W}$ sample irradiated at that temperature, from $5.6 \pm 0.6 \times 10^{21} \mathrm{~m}^{-3}(\mathrm{~W})$ to $45.5 \pm 4.6 \times 10^{21} \mathrm{~m}^{-3}(\mathrm{~W}-5 \mathrm{Ta})$ at $0.4 \mathrm{dpa}$. The average void size is comparable for both samples at $1000{ }^{\circ} \mathrm{C}$ and $0.4 \mathrm{dpa}$, namely $7.1 \pm 1.3 \mathrm{~nm}(\mathrm{~W})$ and $7.4 \pm$ $0.9 \mathrm{~nm}$ (W-5Ta). However, the void size seems to gradually saturate at damage levels $\geq 0.2$ dpa in W-5Ta, whereas it increases at a constant rate in W. Additionally, in both materials the voids present in the microstructure gradually change their shape from spherical to either quadrilateral and/or hexagonal projections at $\geq 0.3$ dpa at both irradiation temperatures - see insets in Fig. $1 \& 2$ and also Fig. 4. The size of the voids did not surpass $8 \mathrm{~nm}$ in either material, see Fig. 3.

\section{Discussion}

The irradiated microstructure at both 800 and $1000{ }^{\circ} \mathrm{C}$ is characterised by the presence of a relatively large number of voids, whose density and average size change with damage level, irradiation temperature and Ta content. The radiation-induced voids seem, in general, to be uniformly and randomly distributed inside the matrix grains. However, we have also detected in some cases a fine denuded zone close to grain boundaries (see Fig. 1), and also a number of voids aligned along a pre-existing dislocation line in the material (e.g. see Fig. 2(e)). Grain boundaries tend to act as effective non-saturable sinks for radiation-induced point defects, leading to a local zone depleted of point defects that reduces markedly the nucleation and growth rate of vacancy clusters and voids [53, 54]. The $a_{0} / 2<111>\{1-10\}$ 
edge dislocation-vacancy interaction in bcc metals is positive for vacancy locations above and below the dislocation slip plane [55]; the dislocation therefore assisting in the nucleation of voids in its vicinity. However, we have not detected the presence of radiation-induced dislocation loops at 800 or $1000{ }^{\circ} \mathrm{C}$. Tungsten sample neutron irradiated at $\mathrm{T}<750{ }^{\circ} \mathrm{C}$ and a damage level of $<1 \mathrm{dpa}$ are characterised by the presence of dislocation loops, whereas at higher irradiation temperatures and damage levels the irradiated microstructure is dominated by the presence of nm-sized voids and the absence of loops [56]. This agrees with data on tungsten and tungsten-rhenium alloys irradiated with neutrons at temperatures up to $800{ }^{\circ} \mathrm{C}$ [57]. The microstructure was dominated by voids in the case of irradiation at $800{ }^{\circ} \mathrm{C}$, and dislocation loops were detected only in $\mathrm{W}$ and $\mathrm{W}-5 \mathrm{Re}$ irradiated at $500{ }^{\circ} \mathrm{C}$. At $1000^{\circ} \mathrm{C}$ the total lack of dislocation loops in helium ion irradiated tungsten was reported due to the proximity of the TEM foil surfaces ensuring a sufficient amount of sinks for rapidly mobile defects and defect clusters at this temperature [58]. Irradiation of $\mathrm{W}$ with $3 \mathrm{MeV} \mathrm{Cu}$ ions at $\sim 770^{\circ} \mathrm{C}$ led to the formation of voids of $\sim 2.1 \mathrm{~nm}$ in size with continuous growing up to $1 \mathrm{dpa}$ [59]. At those elevated temperatures, interstitial dislocation loops would be unstable and emit self-interstitial atoms, or glide to the free sample surface [41]. The vacancy-type loops that would have formed at temperatures $>600{ }^{\circ} \mathrm{C}$, would transit into a more stable void configuration at temperatures close to $1000{ }^{\circ} \mathrm{C}$ [41]. For the potential growth of a void defect, a certain concentration of vacancies entering the void is required which depends on size of the void embryo at a given temperature and damage level [60]. Once reached a critical size, voids would continue growing by absorbing additional mobile vacancies from the matrix. All TEM-visible voids in $\mathrm{W}$ and $\mathrm{W}-5 \mathrm{Ta}$ were no smaller than $1.5-2 \mathrm{~nm}$ at the lowest irradiation level of $0.03 \mathrm{dpa}$. Hence, an incubation period, essential to achieve a necessary vacancy concentration, precedes a noticeable increase in void size. Similar effect was found in tungsten irradiated by $10 \mathrm{keV} \mathrm{He}^{+}$when the resulting helium bubble size enlarged from 
$\sim 3 \mathrm{~nm}$ at $800^{\circ} \mathrm{C}$ to $\sim 5 \mathrm{~nm}$ at $1200^{\circ} \mathrm{C}$ [61]. This was attributed to the thermal emission of vacancies from those void embryos, which did not reach a critical size, while voids that reached the critical minimum dimension, continued their growth partially in expense of the emission of vacancies [62].

The population of voids present in irradiated $\mathrm{W}$ decreases in density when increasing the irradiation temperature from 800 to $1000{ }^{\circ} \mathrm{C}$, whereas the average void size increases, in agreement with previous work on neutron irradiated $\mathrm{W}$ samples to $\sim 9.5 \mathrm{dpa}$ that present a void swelling peak at $0.31 T_{m}=1060{ }^{\circ} \mathrm{C}[20,44]$. At damage levels $\geq 0.2 \mathrm{dpa}$, soft impingement starts to occur, so that voids have an enhanced probability of growing by absorption of free vacancies or void coalescence, as compared to the nucleation of additional voids. The reduction of void density at higher temperatures in tungsten is due to the enhanced mobility of vacancy-type defects and the corresponding reduction in the thermal equilibrium concentration of vacancies at elevated temperatures. At these high temperatures, the system dissociates quickly, causing single vacancies to annihilate rather than persisting in the system to then allow the formation of voids. Similarly, at low enough temperatures, vacancy mobility becomes sufficiently limited that voids may form; this indicates the presence of a temperature envelope where void formation would be more evident.

In contrast, the presence of $5 \mathrm{wt} . \% \mathrm{Ta}$ in solid solution precludes the formation of voids at $800{ }^{\circ} \mathrm{C}$ up to a damage level of $0.3 \mathrm{dpa}$. However, a significant excess of radiation-induced vacancies does exist in the microstructure, so that voids are detected after the sample postirradiation annealing at $1000{ }^{\circ} \mathrm{C}$ for $15 \mathrm{~min}$. First-principle calculations revealed that a binding energy between Ta and a monovacancy is from -0.1 to $-0.3 \mathrm{eV}$ for the first-to-third nearest-neighbour positions [63], which indicates a repulsive solute-vacancy interaction. The binding energy of two defects $\left(\mathrm{A}_{1}, \mathrm{~A}_{2}\right)$ is defined as:

$$
E_{b}^{A_{1}-A_{2}}=E_{\text {tot }}^{A_{1}}+E_{\text {tot }}^{A_{2}}-E_{b}^{A_{1}+A_{2}}-E_{\text {tot }}^{\text {bulk }}
$$


where $E_{\text {tot }}^{A_{1}}$ and $E_{\text {tot }}^{A_{2}}$ are the total energies of the supercell with $\mathrm{A}_{1}$ and $\mathrm{A}_{2}$, respectively, $E_{b}^{A_{1}+A_{2}}$ is the total energy of the supercell containing both $\mathrm{A}_{1}$ and $\mathrm{A}_{2}$, and $E_{\text {tot }}^{\text {bulk }}$ is the total energy of perfect $\mathrm{W}$ bulk in the supercell. The thermal vacancy-mediated diffusion of $\mathrm{Ta}$ in $\mathrm{W}$ is relative slow, with an activation energy of $\mathrm{E}^{\mathrm{a}}=6.20 \mathrm{eV}$ and a pre-exponential factor of $D_{0}=6.20 \times 10^{-4} \mathrm{~m}^{2} / \mathrm{s}$ [34]. The consequence is an effective vacancy trap nearby oversized Ta solute atoms [64], which leads to the hindrance of vacancy migration and void formation at $800^{\circ} \mathrm{C}$ up to the maximum damage level of this study, so that the void swelling regime is shifted to higher temperatures, and at $1000{ }^{\circ} \mathrm{C}$ the formation of new voids dominates over their growth [65]. Hence, it requires more thermal energy to start vacancy movement and to initiate coalescing coalescence in W-5Ta. Moreover, the average void size seems to gradually saturate at damage levels $>0.2$ dpa at the higher irradiation temperature of $1000{ }^{\circ} \mathrm{C}$.

At $\geq 0.3 \mathrm{dpa}$, the voids present in both materials transit steadily from spherical to faceted shapes with facet planes of $\{110\}$, as dictated by the anisotropy of the surface energy and by the preferential absorption of diffusing vacancies on specific plane orientations with respect to the void surface [66]. The fraction of square voids then rises and amounts to $30 \%$ in $\mathrm{W}$ at $800^{\circ} \mathrm{C}$ and $12 \%$ in $\mathrm{W}-5 \mathrm{Ta}$ at $1000^{\circ} \mathrm{C}$ of the total amount of faceted voids at a maximum of $0.4 \mathrm{dpa}$. The presence of Ta repels vacancies and therefore delays their growth and transition into faceted shapes.

\section{Conclusions}

The in-situ TEM study of the microstructure evolution of $\mathrm{W}$ material proton-irradiated, step-wise up to an accumulated damage level of $0.4 \mathrm{dpa}$, revealed the presence of a population of voids that are in general randomly and uniformly distributed inside the grains of the matrix. An increase in irradiation temperature from 800 to $1000{ }^{\circ} \mathrm{C}$ causes a significant decrease in void density, and concomitantly an increase in average void size. Soft 
impingement seems to take place at $\geq 0.2 \mathrm{dpa}$ where the void size experiences a more rapid increase with the damage level. The presence of only $5 \mathrm{wt} . \% \mathrm{Ta}$ in solid solution hinders the diffusion of free radiation-induced vacancies at $800{ }^{\circ} \mathrm{C}$, and consequently precludes the formation of voids up to $0.3 \mathrm{dpa}$. Moreover, solute Ta atoms also induce a remarkable increase in void density at $1000{ }^{\circ} \mathrm{C}$ as compared to $\mathrm{W}$ under equivalent irradiation conditions, and a gradual progression in average void size towards saturation at $\geq 0.2$ dpa. Furthermore, a significant number of voids in both materials, initially formed as spherical embryos, experience a progressive transition to a faceted shape at $\geq 0.3 \mathrm{dpa}$.

\section{Acknowledgments}

The authors of this work acknowledge access to the MIAMI-II facility through the EPSRC-funded mid-range facility, the UK National Ion Beam Centre (NS/A000059/1). In addition, access to sample preparation equipment provided by the Dalton Cumbrian Facility of The University of Manchester is acknowledged. Authors I.I., M.J.D.R. and S.C.M. are supported through the Sêr Cymru Nuclear Futures Institute funded through WEFO (Wales). We would particularly like to thank Prof. W.E. Lee for his support and guidance.

\section{References}

[1] D. Hancock, D. Homfray, M. Porton, I. Todd, B. Wynne, Refractory metals as structural materials for fusion high heat flux components. J. Nucl. Mater. 512 (2018) 169-183.

[2] T. Hirai, S. Panayotis, V. Barabash, C. Amzallag, F. Escourbiac, A. Durocher et al., Use of tungsten material for the ITER divertor. Nucl. Mater. Energy 9 (2016) 616-22.

[3] M. Rieth, S.L. Dudarev, S.M. Gonzalez de Vicente, J. Aktaa, T. Ahlgren, S. Antusch, et al., Recent progress in research on tungsten materials for nuclear fusion applications in Europe. J. Nucl. Mater. 432 (2013) 482-500. 
[4] S.J. Zinkle, A. Mösslang, T. Muroga, H. Tanigawa, Multimodal options for materials research to advance the basis for fusion energy in the ITER era. Nucl. Fusion 53 (2013) 104024 (13pp).

[5] R.G. Abernethy, Predicting the performance of tungsten in a fusion environment: a literature review, Mater. Sci. Technol. 33 (2017) 388.

[6] C. Thomser, V. Bailescu, S. Brezinsek, J.W. Coenen, H. Greuner, T. Hirai et al., Plasma Facing Materials for the JET ITER-Like Wall. Fusion Sci. Technol. 62 (2012) 1-8.

[7] A. Widdowson, E. Alves, A. Baron-Wiechec, N.P. Barradas, N. Catarino, J.P. Coad et al., Overview of the JET ITER-like wall divertor. Nucl. Mater. Energy 12 (2017) 499-505.

[8] R. Villari, V. Barabash, F. Escourbiac, L. Ferrand, T. Hirai, V. Komarov et al., Nuclear analysis of the ITER full-tungsten divertor. Fusion Eng. Des. 88 (2013) 2006-10.

[9] S.Heuer, Th.Weber, G.Pintsuk, J.W.Coenen, J.Matejicek, Ch.Linsmeier, Aiming at understanding thermo-mechanical loads in the first wall of DEMO: Stress-strain evolution in a Eurofer-tungsten test component featuring a functionally graded interlayer. Fus. Eng. Design 135 (2018) 141-153.

[10] A. Li-Puma, M. Richou, P. Magaud, M. Missirlian, E. Visca, V.P. Ridolfini, Potential and limits of water cooled divertor concepts based on monoblock design as possible candidates for a DEMO reactor. Fusion Eng. Des. 88 (2013) 1836-1843.

[11] S.J. Zinkle, N.M. Ghoniem, Operating temperature windows for fusion reactor structural materials. Fusion Eng. Des. 51-52 (2000) 55-71.

[12] T. Shen,Y. Dai,Y. Lee, Microstructure and tensile properties of tungsten at elevated temperatures. J. Nucl. Mater. 468 (2016) 348-354.

[13] P. Gumbsch. Brittle fracture and the brittle-to-ductile transition of tungsten, J. Nucl. Mater. 323 (2003) 304-312. 
[14] B.Gludovatz, S.Wurster, A.Hoffmann, R.Pippan, Fracture toughness of polycrystalline tungsten alloys. Int. J. Refract. Met. Hard Mater. 28 (2010) 674-678.

[15] E. Gaganidze, D. Rupp, J. Aktaa, Fracture behaviour of polycrystalline tungsten. J. Nucl. Mater. 446 (2014) 240-245.

[16] H. Bolt, V. Barabash, G. Federici, J. Linke, A. Loarte, J. Roth, K. Sato, Plasma facing and high heat flux materials - needs for ITER and beyond. J. Nucl. Mater. 307-311 (2002) 43-52.

[17] I.V. Gorynin, V.A. Ignatov, V.V. Rybin, S.A. Fabritsiev, V.A. Kazakov, V.P. Chakin, et al., Effects of neutron irradiation on properties of refractory metals. J. Nucl. Mater. 191-194 (1992) 421-425.

[18] L.K. Keys, J.P. Smith, J. Moteff, Stage III recovery in neutron irradiated tungsten. Scripta Metall. 1 (1967) 71-72.

[19] V.K. Sikka, J. Moteff, "Rafting" in neutron irradiated tungsten. J. Nucl. Mater. 46 (1973) 217-219.

[20] T. Koyanagi, N.A.P. Kiran Kumar, T. Hwang, L.M. Garrison, X. Hu, L.L. Snead, Y. Katoh, Microstructural evolution of pure tungsten neutron irradiated with a mixed energy spectrum. J. Nucl. Mater. 490 (2017) 66-74.

[21] J.M. Galligan, T. Oku, Dislocation Loops in Neutron Irradiated Tungsten. Phys. Stat. Sol. 36 (1969) K79-K82.

[22] T. Koyagani, N.A.P. Kiran Kumar, T. Hwang, L.M. Garrison, X. Hu, L.L. Snead, Y. Katoh. Microstructural evolution of pure tungsten neutron irradiated with a mixed energy spectrum. J. Nucl. Mater. 490 (2017) 66-74.

[23] X. Hu, T. Koyanagi, M. Fukuda, N.P.P. Kiran Kumar, L.L. Snead, B.D. Wirth, Y. Katoh, Irradiation hardening of pure tungsten exposed to neutron irradiation. J. Nucl. Mater. 480 (2016) 235-243. 
[24] X. Hu, C.M. Parish, K. Wang, T. Koyamagi, B.P. Eftink, Y. Katoh, Transmutationinduced precipitation in tungsten irradiated with a mixed energy spectrum. Acta Mater. 165 (2019) 51-61.

[25] R.W. Harrison, On the use of ion beams to emulate the neutron irradiation behaviour of tungsten. Vacuum 160 (2019) 355-370.

[26] X. Yi, M.L. Jenkins, M. Briceno, S.G. Roberts, Z. Zhou, M.A. Kirk, In-situ study of self-ion irradiation damage in $\mathrm{W}$ and W-5Re at $500^{\circ} \mathrm{C}$. Phil. Mag. 93 (2013) 1715-1738.

[27] F. Ferroni, X. Yi, K. Arakawa, S.P. Fitzgerald, P.D. Edmonson, S.G. Roberts, High temperature annealing of ion irradiated tungsten. Acta Mater. 90 (2015) 380-393.

[28] M. Rieth, S.L. Dudarev, S.M. Gonzalez de Vicente, J.Aktaa, T.Ahlgren, S.Antusch, et al., A brief summary of the progress on the EFDA tungsten materials program. J. Nucl. Mater. 442 (2013) S173-S180.

[29] D. Jiang, Q. Wang, W. Hu, Z. Wei, J. Tong, H. Wan, The effect of tantalum (Ta) doping on mechanical properties of tungsten (W): A first-principles study. J. Mater. Res. 31 (2016) $3401-3408$.

[30] Z. Wang, Y. Yuan, K. Arshad, J. Wang, Z. Zhou, J. Tang, G.-H. Lu, Effects of tantalum concentration on the microstructures and mechanical properties of tungsten-tantalum alloys. Fusion Eng. Des. 125 (2017) 496-502.

[31] P.E.A. Turchi, A. Gonis, V. Drchal, J. Kudmonvský, First-principles study of stability and local order in substitutional Ta-W alloys. Phys. Rev. B 64 (2001) 085112 (8pp).

[32] D.E.J. Armstrong, A.J. Wilkinson, S.G. Roberts, Mechanical properties of ion-implanted tungsten-5wt,\% tantalum. Phys. Scr. T145 (2011) 014076 (4pp).

[33] X. Yi, M.L. Jenkins, K. Hattar, P.D. Edmondson, S.G. Roberts, Characterisation of radiation damage in $\mathrm{W}$ and $\mathrm{W}$-based alloys from $2 \mathrm{MeV}$ self-ion near-bulk implantations. Acta Mater. 92 (2015) 163-177. 
[34] A. Xu, D.E.J. Armstrong, C. Beck, M.P. Moody, G.D.W. Smith, P.A.J. Bagot et al., Ionirradiation induced clustering in W-Re-Ta, W-Re and W-Ta alloys: An atom probe tomography and nanoindentation study. Acta Mater. 124 (2017) 71-78.

[35] I. Ipatova, R.W. Harrison, P.T. Wady, S.M. Shubeita, D. Terentyev, S.E. Donnelly, E. Jimenez-Melero, Structural defect accumulation in tungsten and tungsten-5wt,\% tantalum under incremental proton damage. J. Nucl. Mater. 501 (2017) 329.

[36] W. Setyawan, G. Nandipati, R.J. Kurtz, Ab initio study of interstitial cluster interaction with Re, Os, and Ta in W. J. Nucl. Mater. 484 (2017) 30-41

[37] L.K. Keys, J.Moteff, Neutron irradiation and defect recovery of tungsten. J. Nucl. Mater. 34 (1970) 260-280.

[38] Y.-W. Kim, J.M. Galligan, An annealing study of thermal neutron irradiated tungsten. J. Nucl. Mater. 69 \& 70 (1978) 680-682.

[39] D.N. Seidman, On the point-defect annealing mechanism for stage III recovery in irradiated or quenched tungsten. Scripta Metall. 13 (1979) 251-257.

[40] T. Tanno, M. Fukuda, S. Nogami, A. Hasegawa. Microstructure Development in Neutron Irradiated Tungsten Alloys. Mater. Trans. 52 (2011) 1447-1451.

[41] I. Ipatova, R.W. Harrison, D. Terentyev, S.E. Donnelly, E. Jimenez-Melero, Thermal evolution of the proton irradiated structure in tungsten-5wt\% tantalum, J. Fusion Energy 36 (2017) 234-239.

[42] X. Yi, K. Arakawa, Y. Du, F. Ferroni, W. Han, P. Liu, F. Wan, High-temperature defect recovery in self-ion irradiated W-5 wt\% Ta. Nucl. Mater. Energy 18 (2019) 93-98.

[43] M.R. Gilbert, S.L. Dudarev, P.M. Derlet, D.G. Pettifor, Structure and metastability of mesoscopic vacancy and interstitial loop defects in iron and tungsten. J. Phys.: Condens. Matter 20 (2008) 345214 (10pp). 
[44] J. Matolich H. Nahm, J. Moteff, Swelling in neutron irradiated tungsten and tungsten25 percent rhenium. Scripta Metall. 8 (1974) 837-841.

[45] V.K. Sikka, J. Moteff, Superlattice of voids in neutron-irradiated tungsten. J. Appl. Phys. 43 (1972) 4942-4944.

[46] J. Linke, T. Loewenhoff, V. Massaut, G. Pintsuk, G. Ritz, M. R€odig, A. Schmidt, C. Thomser, I. Uytdenhouwen, V. Vasechko, M. Wirtz, Performance of different tungsten grades under transient thermal loads. Nucl. Fusion 51 (2011) 073017.

[47] Y. Zayachuk, M.H.J. t Hoen, P.A. Zeijlmans van Emmichoven, D. Terentyev, I. Uytdenhouwen, G. van Oost, Nucl., Surface modification of tungsten and tungsten-tantalum alloys exposed to high-flux deuterium plasma and its impact on deuterium retention. Fusion $53(2013) 013013$.

[48] J.A. Hinks, J.A. van den Berg, S.E. Donnelly. MIAMI: Microscope and ion accelerator for materials investigations. J. Vac. Sci. Technol. A-Vac. Surf. Films 29 (2011) 021003 (6pp).

[49] J.F. Ziegler, Stopping of energetic light ions in elemental matter. J. Appl. Phys. 85 (1999) 1249-1272.

[50] J.F. Ziegler, M.D. Ziegler, J.P. Biersack, SRIM - The stopping and range of ions in matter (2010). Nucl. Instrum. Meth. Phys. Res. B 268 (2010) 1818-1823.

[51] ASTM E521-96, Standard Practice for Neutron Radiation Damage Simulation by Charged-particle Irradiation, 2009.

[52] M.L. Jenkins, M.A. Kirk, Characterization of Radiation Damage by Transmission Electron Microscopy, IOP Publishing Ltd, 2001.

[53] B.N. Singh, On the influence of grain boundaries on void growth. Phil. Mag. 28 (1973) 1409-1413. 
[54] D.I.R. Norris, The use of the high voltage electron microscope to simulate fast neutroninduced void swelling in metals. J. Nucl. Mater. 40 (1971) 66.

[55] K.W. Ingle, A.G. Crocker, The interaction between vacancies and $\frac{1}{2}<111>\{1-10\}$ edge dislocation in body centred cubic metals. Acta Metall. 26 (1978) 1461-1469.

[56] A. Hasegawa, M. Fukuda, S. Nogami, K. Yabuuchi, Neutron irradiation effects on tungsten materials, Fusion Eng. Des. 89 (2014) 1568-1572.

[57] M. Fukuda, K. Yabuuchi, S. Nogami, A. Hasegawa, T. Tanaka, Microstructural development of tungsten and tungsten-rhenium alloys due to neutron irradiation in HFIR, J. Nucl. Mater. 455 (2014) 460-463.

[58] R.W. Harrison, G. Greaves, J.A. Hinks, S.E. Donnelly, A study of the effect of helium concentration and displacement damage on the microstructure of tungsten irradiation with helium ions, J. Nucl. Mater. 495 (2017) 492-503.

[59] O. El-Atwani, E. Esquivel, M. Efe, E. Aydogan, Y.Q. Wanga, E. Martinez, S.A. Maloy, Loop and void damage during heavy ion irradiation on nanocrystalline and coarse grained tungsten: Microstructure, effect of dpa rate, temperature, and grain size, Acta Materialia, 149 (2019) 206-219.

[60] A.A. Semenov, C.H.Woo, Void nucleation at elevated temperatures under cascadedamage irradiation. Phys Rev B 2002; 66:024118.

[61] Yi X, Arakawa K, Nguyen-Manh D, Ferroni F, Liu P, Han W, et al. A study of helium bubble production in $10 \mathrm{keV} \mathrm{He}+$ irradiated tungsten. Fusion Eng Des 2017;125:454-7.

[62] Krishan K, Nandedkar R V. Mechanisms for radiation-induced shrinkage of voids. Nature 1979; 280: 253.

[63] X.-S. Kong, X. Wu, Y.-W. You, C.S. Liu, Q.F. Fang, J.-L. Chen et al., First-principles calculations of transition metal-solute interactions with point defects in tungsten. Acta Mater. 66 (2014) 172-183. 
[64] F.A. Smidt Jr., J.A. Sprague, Suppression of void nucleation by a vacancy trapping mechanism. Scripta Metall. 7 (1973) 495-501.

[65] Lam NQ, Okamoto PR, Wiedersich H. Effects of solute segregation and precipitation on void swelling in irradiated alloys. J Nucl Mater 1978; 74: 101-13.

[66] W.B. Liu, N. Wang, Y.Z. Ji, P.C. Song, C. Zhang, Z.G. Yang et al., Effects of surface energy anisotropy on void evolution during irradiation: A phase-field model. J. Nucl. Mater. 479 (2016) 316-322. 


\section{Figure captions}

Fig. 1. In-situ observation of void growth, together with changes in void shape (insets), in W under increasing damage levels induced by a $40 \mathrm{keV}$ proton beam at $800{ }^{\circ} \mathrm{C}$ : (a) $0.03 \mathrm{dpa}$, (b) $0.1 \mathrm{dpa}$, (c) $0.3 \mathrm{dpa}$, (d) $0.4 \mathrm{dpa}$; and $1000^{\circ} \mathrm{C}$ : (e) $0.3 \mathrm{dpa}$, (f) $0.4 \mathrm{dpa}$. Yellow dotted line denotes denuded zone.

Fig. 2. In-situ observation of void growth, together with changes in void shape (insets) in W-5Ta material under increasing damage levels induced by $40 \mathrm{keV}$ proton bombardment at $800{ }^{\circ} \mathrm{C}$ : (a) $0.03 \mathrm{dpa}$, (b) $0.1 \mathrm{dpa}$, (c) $0.3 \mathrm{dpa}$, (d) after post-irradiation annealing at $1000^{\circ} \mathrm{C}$; and $1000^{\circ} \mathrm{C}$ at $800{ }^{\circ} \mathrm{C}$ : (e) $0.03 \mathrm{dpa}$, (f) $0.1 \mathrm{dpa}$, (g) $0.3 \mathrm{dpa}$, (h) $0.4 \mathrm{dpa}$. Radiation-induced voids were not detected in the irradiated material at $800{ }^{\circ} \mathrm{C}$, but can be seen in the same sample after post-irradiation annealing at $1000{ }^{\circ} \mathrm{C}$.

Fig. 3. Average size and number-density of voids in $\mathrm{W}$ and W-5Ta alloy as a function of damage level, at the irradiation temperature of either 800 or $1000{ }^{\circ} \mathrm{C}$. Voids were not detected in the W-5Ta proton irradiated up to a damage level of $0.3 \mathrm{dpa}$ at $800{ }^{\circ} \mathrm{C}$.

Fig. 4. Void agglomeration and change in void shape in W-5Ta at selected damage levels, induced by $40 \mathrm{keV}$ proton bombardment at $1000^{\circ} \mathrm{C}$ : (a) $0.17 \mathrm{dpa}$, (b) $0.2 \mathrm{dpa}$, (c) $0.3 \mathrm{dpa}$, (d) 0.4 dpa.

Fig. S1. Bright field TEM imaging of radiation-induced voids in $\mathrm{W}$ at the temperature of $800{ }^{\circ} \mathrm{C}$ and the damage level of $0.1 \mathrm{dpa}$, based on the out-of-focus imaging technique with selected defocus values up to $+/-1 \mu \mathrm{m}$.

Fig. S2. Bright field TEM images of voids in W-5Ta proton-irradiated at $1000{ }^{\circ} \mathrm{C}$ and to a damage level of at $0.2 \mathrm{dpa}$. The images were taken using the out-of-focus imaging technique with the defocus value of $+/-500 \mathrm{~nm}$. Dislocations present in the micrographs correspond to pre-existing dislocations prior to irradiation. 


\section{Highlights}

1. Addition of $\mathrm{Ta}$ to $\mathrm{W}$ reduces vacancy mobility and delays void formation at $800^{\circ} \mathrm{C}$

2. Ta atoms induce a significant increase in void density at $1000^{\circ} \mathrm{C}$ as compared to W

3. At $1000^{\circ} \mathrm{C}$ and $\geq 0.2$ dpa void size saturates in $\mathrm{W}-5 \mathrm{Ta}$, but it still increases in $\mathrm{W}$

4. Voids in $\mathrm{W}$ and $\mathrm{W}-5 \mathrm{Ta}$ transit from spherical to faceted shape at $\geq 0.3 \mathrm{dpa}$

5. At $1000^{\circ} \mathrm{C}$ and $0.4 \mathrm{dpa}$ fraction of faceted voids is $30 \%$ in $\mathrm{W}$ and $12 \%$ in $\mathrm{W}-5 \mathrm{Ta}$ 


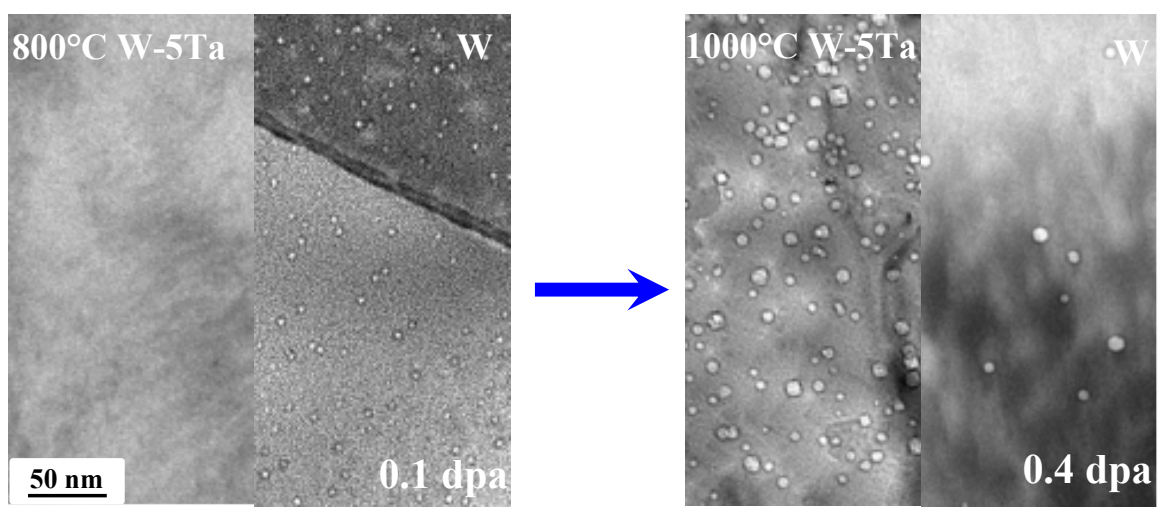




\section{Void evolution in tungsten and tungsten-5wt.\% tantalum}

\section{under in-situ proton irradiation at 800 and $1000{ }^{\circ} \mathrm{C}$}

I. Ipatova ${ }^{a^{*}}$, R.W. Harrison ${ }^{b, c}$, S. E. Donnelly ${ }^{b}$, M.J.D. Rushton ${ }^{a}$, S.C. Middleburgh ${ }^{\mathrm{a}}$,

E. Jimenez-Melero ${ }^{\mathrm{d}}$

${ }^{a}$ Nuclear Futures Institute, Bangor University, Dean Street,

Bangor Gwynedd, LL57 1 UT, UK

${ }^{b}$ School of Computing and Engineering, University of Huddersfield,

Huddersfield, HD1 3DH, UK

'School of Mechanical, Aerospace and Civil Engineering, Materials Performance Centre,

The University of Manchester, Manchester M13 9PL, UK

${ }^{d}$ Materials Performance Centre, School of Materials, The University of Manchester,

Manchester M13 9PL, UK

Corresponding author (*):

Nuclear Futures Institute

Bangor University

Dean Street

Bangor, Gwynedd

LL57 1UT

United Kingdom

Tel.: +44 7849290480

Email: i.ipatova@bangor.ac.uk 


\begin{abstract}
We have probed void evolution in polycrystalline $\mathrm{W}$ and $\mathrm{W}-5 \mathrm{wt} . \%$ Ta material at 800 and $1000{ }^{\circ} \mathrm{C}$, by transmission electron microscopy during in-situ irradiation with a $40 \mathrm{keV}$ proton beam. The presence of radiation-induced dislocation loops was not observed prior to void formation at those elevated temperatures. The damaged $\mathrm{W}$ microstructure was characterised by the presence of a population of randomly distributed voids, whose number density reduces when the irradiation temperature increases. Soft impingement of voids becomes noticeable at damage levels $\geq 0.2 \mathrm{dpa}$. In contrast, the excess of free vacancies in the W-5wt.\%Ta material irradiated at $800{ }^{\circ} \mathrm{C}$ only leads to the formation of visible voids in this TEM study ( $\geq 2 \mathrm{~nm}$ ) after post-irradiation annealing of the sample at $1000{ }^{\circ} \mathrm{C}$. Solute Ta atoms also cause a significant increase in the number density of voids when comparing the microstructure of both materials irradiated at $1000^{\circ} \mathrm{C}$, and a gradual progression towards saturation in average void size at $\geq 0.2 \mathrm{dpa}$. Moreover, we have detected a progressive transition from a spherical to a faceted shape in a number of voids present in both materials at damage levels $\geq 0.3$ dpa.
\end{abstract}

Keywords: refractory metals, materials for fusion, radiation damage, faceted voids, transmission electron microscopy 


\section{Introduction}

Tungsten has traditionally stood out within the refractory metal group as the prime plasma-facing candidate for armour components of magnetically-confined tokamak fusion reactors. Tungsten may potentially be used in the future, for the underlying cooling structures as well, if taking advantage of the incipient additive manufacturing technologies for optimised geometries $[1,2]$. The attractiveness of tungsten is due to its high melting point $\left(T_{m}=3422^{\circ} \mathrm{C}\right)$ and its resistance to sputtering from accidental plasma-material interactions, together with suitable thermal conductivity, shock resistance and high-temperature strength [3-5]. Tungsten was used as a $\sim 25 \mu \mathrm{m}$-thick coating on the carbon fibre composite divertor tiles during the second JET ITER-like wall campaign of 2013-2014 [6, 7]. In ITER, tungsten tiles will also be placed on the top section of the arched stainless-steel plasma confinement construction. During regular operation modes, the full-tungsten armour will experience heat loads of $\sim 6.5-10 \mathrm{MW} / \mathrm{m}^{2}$, attaining values close to $20 \mathrm{MW} / \mathrm{m}^{2}$ during short transient events. Additionally, a $14 \mathrm{MeV}$ neutron-induced damage level of $\sim 0.1$ dpa is predicted to be accumulated by the tungsten monoblocks after the 4-year ITER nuclear phase prior to the cassette replacement of the first divertor, and $\sim 0.5 \mathrm{dpa}$ for permanent divertor components during ITER's end-of-life operation [8]. Furthermore, current blanket designs for the future fusion demonstration power plant (DEMO) are based on a first wall in which the tungsten armour is joined to a structure made of Reduced Activation Ferritic Martensitic (RAFM) steel [9]. Water-cooled DEMO divertor designs under consideration are also based on ITER-like tungsten monoblocks [10].

The recommended low-temperature limit for safe operation of body-centred cubic (bcc) metals such as tungsten is dictated by radiation-induced hardening and embrittlement, occurring even for doses $\leq 1 \mathrm{dpa}$ [11]. Unfortunately, tungsten is inherently brittle at low temperatures, being characterized by a ductile-to-brittle transition temperature (DBTT) in the 
range of $\sim 200-400{ }^{\circ} \mathrm{C}$. Both the value of the DBTT and of the low-temperature fracture toughness depend on the material processing route [12], and consequently on the microstructure and its anisotropy [13-15]. Additionally, exposure to neutron bombardment can shift the DBTT up to $\sim 800-1000{ }^{\circ} \mathrm{C}$ and exacerbates the propensity for brittle failure at lower temperatures $[11,16,17]$. Tungsten irradiated with thermal or mixed neutrons to a damage level of $<1$ dpa and at temperatures below the vacancy-mediated stage III recovery, i.e. below $\sim 0.15 T_{m}$ depending on neutron energy spectrum and fluence, presents primarily a population of $a_{0} / 2<111>$ interstitial dislocation loops [18-20]. At higher temperatures, those loops tend to migrate and form larger interstitial-type structures [19]. Relatively high fast/mixed energy neutron fluences, at temperatures as low as $70{ }^{\circ} \mathrm{C}$, also induce the occurrence of diffuse vacancy clusters and voids [21, 22]. Additionally, an increase in damage level to $>1$ dpa leads to the formation of nano-scale precipitates, involving Re and Os atoms resulting from transmutation [20]. These dominate radiation-induced hardening at relatively high damage levels [23]. Radiation-induced dislocation loops and voids act as effective trapping sites for mobile species and promote the nucleation of W-Re-Os precipitates [24]. In recent years ion irradiation experiments, especially those coupled with in-situ transmission electron microscopy, have shed complementary light on radiationinduced lattice defect evolution [25]. 1-D loop hopping has been observed in-situ in the temperature range of $300-700{ }^{\circ} \mathrm{C}$, together with loop growth primarily by absorption $[26,27]$.

A promising strategy to make $\mathrm{W}$ more ductile is to introduce high-temperature elements (e.g. Ta, V, Ti, Mo, Re) either in solid solution or as short fibres in the $\mathrm{W}$ matrix [28-30]. In the former case, the predicted W-Ta phase diagram confirms that Ta remains in solid solution at concentrations $<10 \mathrm{wt} . \% \mathrm{Ta}$, whereas there is a tendency to form either B2 (CsCl-type) or $\mathrm{DO}_{3}\left(\mathrm{Fe}_{3} \mathrm{Al}\right.$-type) ordered phases depending on temperature up to $727^{\circ} \mathrm{C}$ and on Ta content $>10 \mathrm{wt} . \%$ [31]. Self-ion irradiation of $\mathrm{W}-5 \mathrm{Ta}(\mathrm{W}-5 \mathrm{wt} \% \mathrm{Ta})$ at $300-500{ }^{\circ} \mathrm{C}$ up to 
33 dpa does not induce significant Ta clustering. However, the presence of 5wt.\%Ta hinders the formation of radiation-induced Re-rich clusters, and also causes a higher dislocation loop density as compared to irradiated $\mathrm{W}$ under equivalent experimental conditions, but with a smaller average loop size [32-34]. Moreover, the loop size in W-5Ta proton-irradiated at $350{ }^{\circ} \mathrm{C}$ saturates at only $0.3 \mathrm{dpa}$, whereas the loop length in $\mathrm{W}$ continues to increase with damage level, giving rise to the formation of dislocation strings [35]. Recently systematic DFT simulations of tungsten self-interstitial atom clusters have revealed that Ta strongly repels interstitial clusters, especially when Ta is located on the periphery of the cluster [36].

In contrast, the upper temperature limit of structural materials such as $\mathrm{W}$ and its alloys is controlled by thermal creep, high-temperature helium embrittlement and void swelling [11]. In this respect, a significant number of annealing experiments have been reported in tungsten samples that had previously been irradiated at different low temperatures and damage levels, and with varying neutron energy spectra [20, 37-40], proton [41] or self-ion $[27,42]$ beams. Stage III recovery $\left(\geq 0.15 T_{m}\right)$ is characterised by vacancy migration, whereas in stage IV $\left(\geq 0.22 T_{m}\right)$ there is migration of vacancy clusters and vacancy-impurity complexes that become unstable and start emitting vacancies at $\geq 0.31 T_{m}$ (stage $\mathrm{V}$ ). The interstitial-type $a_{0} / 2<111>$ dislocation loops emit self-interstitial atoms at temperatures $>500{ }^{\circ} \mathrm{C}$. The vacancy excess in the matrix evolves into vacancy-type $a_{0} / 2<111>$ dislocation loops at $600-900{ }^{\circ} \mathrm{C}$ and into voids at $>1000{ }^{\circ} \mathrm{C}$ [41]. Energy calculations of mesoscopic defect configurations in $\mathrm{W}$ using many-body interatomic potentials revealed that spherical voids are the most energetically favourable configuration, and vacancy-type loops therefore represent metastable configurations that would evolve into a void structure [43]. In neutron irradiated $\mathrm{W}$, voids are already visible at $\sim 430{ }^{\circ} \mathrm{C}$, with a maximum in void swelling at $\sim 0.31 \mathrm{Tm}=$ $1060{ }^{\circ} \mathrm{C}[20,44]$. Voids larger than $10 \mathrm{~nm}$ were faceted, with facet planes of $\{211\}$ and $\{110\}[20]$. A void lattice structure, characterised by a void lattice parameter of $195 \AA$ and a 
lattice parameter to average void size ratio of about six, was observed in neutron irradiated W at $550{ }^{\circ} \mathrm{C}$ to a neutron fluence of $1 \times 10^{22}$ neutrons $/ \mathrm{cm}^{2}$ [45]. Moreover, a very low density of interstitial loops was detected in the temperature range of $500-800{ }^{\circ} \mathrm{C}$ up to 2.2 dpa [23]. Despite the wealth of reports about low-temperature radiation damage structures in $\mathrm{W}$ and alloys, their thermal stability post irradiation, and the formation of radiation-induced void structures in neutron irradiated $\mathrm{W}$, the formation of defect structures in $\mathrm{W}$ at elevated temperatures and the role of Ta remain largely unexplored. In this study, we focus on in-situ monitoring of radiation-induced void evolution in $\mathrm{W}$ and $\mathrm{W}-5 \mathrm{Ta}$ at damage levels $\leq 0.4 \mathrm{dpa}$ and at two target temperatures: $800{ }^{\circ} \mathrm{C}$ and $1000{ }^{\circ} \mathrm{C}$.

\section{Experimental}

The initial W (99.95\%) was provided by Goodfellow Cambridge Ltd. in the form of $1 \mathrm{~mm}$ thick sheet. The as-received $\mathrm{W}$ material was annealed in vacuum at $1400{ }^{\circ} \mathrm{C}$ for $2 \mathrm{~h}$ for recrystallization. The W-5Ta material was produced by powder metallurgy and provided by Plansee AG. The material was double forged and then annealed at $1600{ }^{\circ} \mathrm{C}$ for $1 \mathrm{~h} \mathrm{[46].} \mathrm{After}$ delivery, the material was annealed for $1 \mathrm{~h}$ at $1000{ }^{\circ} \mathrm{C}$ for degassing [47]. Afterwards, smaller samples of $2 \times 2 \mathrm{~cm}^{2}$ were cut and annealed at $1400{ }^{\circ} \mathrm{C}$ for $2 \mathrm{~h}$ to remove the defects from machining. TEM discs of both materials were prepared by mechanical pre-thinning, using $\mathrm{SiC}$ abrasive papers with successively smaller grit size (from grit 220 up to 4000). Then the procedure was followed by electropolishing at a temperature of $\sim-5{ }^{\circ} \mathrm{C}$ using a Struers Tenupol-5 unit and an electrolyte comprising an aqueous solution of $0.5 \mathrm{wt} \% \mathrm{Na}_{2} \mathrm{~S}$ for electropolishing $\mathrm{W}$, or a mixture of $15 \mathrm{vol} \%$ sulphuric acid $(95 \%)$ and $85 \mathrm{vol} \%$ methanol in the case of W-5Ta. The grain structure of both materials is presented in Fig. 1. The average grain size was $2.3 \pm 0.7 \mathrm{~mm}(\mathrm{~W}-5 \mathrm{Ta})$ and $3.9 \pm 0.8 \mathrm{~mm}(\mathrm{~W})$.

In-situ irradiation experiments were performed on the MIAMI-II TEM/ion accelerator system located at the University of Huddersfield [48]. The in-situ irradiation facility 
comprises a Hitachi H-9500 transmission electron microscope (TEM) with a maximum operating voltage of $300 \mathrm{kV}$, coupled to a $350 \mathrm{kV}$ National Electrostatics Corporation ion accelerator incorporating a Danfysik 921A ion source capable of providing ions of most species up to $\mathrm{Au}$. The ion beam is incident on the sample at an angle of $18.7^{\circ}$ to the electron beam. A double-tilt heating holder (Gatan Model 652) was used to reach the target temperature, i.e. 800 or $1000{ }^{\circ} \mathrm{C}$. Equivalent TEM discs with an average thickness of 100-110 nm, as determined by Convergent Electron Beam Diffraction (CBED) prior to the experiment, were irradiated with $40 \mathrm{keV}$ protons at these two temperatures and at increasing damage levels up to $0.4 \mathrm{dpa}$ for each material. The W-5Ta sample that had been irradiated, step-wise, up to $0.3 \mathrm{dpa}$ at $800{ }^{\circ} \mathrm{C}$ was subsequently annealed at $1000{ }^{\circ} \mathrm{C}$ for $15 \mathrm{~min}$. The main parameters for each irradiation experiment are collected in Table 1. The simulated damage profile was calculated using the SRIM software with the quick Kinchin-Pease approach [49, 50], using an average displacement energy of $90 \mathrm{eV}$ [51] and default values for other software settings. The total current deposited on the sample is given in Table 1, and it was predicted that $97 \%$ of the incoming protons would have been transmitted through the foil. The Bragg peak for $40 \mathrm{keV}$ protons in $\mathrm{W}$ occurs at $130 \mathrm{~nm}$ [35]. The reported damage levels correspond to the average values in the foil thickness. Micrographs were recorded along the zone axes $<100>$ and $<111>$ during the step-wise increase in damage level. The "out-of-focus" Fresnel imaging technique was used for bright-field void detection. Due to the inner potential difference between the void and the surrounding matrix, voids appear as white dots surrounded by black Fresnel fringes when recorded in an under-focused condition, and as dark dots with bright fringes in an over-focused condition. At each new damage level, a through-focal series of micrographs was taken with a defocus value $\Delta f \leq 1 \mu \mathrm{m}$ to feature voids of $\geq 1 \mathrm{~nm}$ in diameter [52]. The average void size was determined using the micrographs taken in over-focus condition and all voids visible in TEM were $\geq 2 \mathrm{~nm}$. 


\section{Results}

The occurrence and evolution of radiation-induced voids at the two selected temperatures are displayed in Fig. 2 and 3 for $\mathrm{W}$ and $\mathrm{W}-5 \mathrm{Ta}$, respectively. The main microstructural parameters characterizing the void structure are collected in Table 2. In both materials and at both irradiation temperatures, the damaged structure was characterised by the formation of voids that changed in number, size and morphology with increasing damage level. The presence of radiation-induced dislocation loops was not detected at any of those irradiation temperatures. The number density of voids in the $\mathrm{W}$ sample irradiated at $800{ }^{\circ} \mathrm{C}$ increases continuously up to the maximum damage level of $0.4 \mathrm{dpa}$, with a faster increase up to $0.2 \mathrm{dpa}$, and a somewhat lower rate of change with damage level beyond $0.2 \mathrm{dpa}$. This transition coincides with a higher increase in the average void size with damage level at $\geq 0.2$ dpa (Fig. 5). At the irradiation temperature of $1000{ }^{\circ} \mathrm{C}, \mathrm{W}$ shows a similar trend in void evolution with damage level, but with a significantly lower density and a larger average void size. At $0.4 \mathrm{dpa}$, the void densities are $(52.5 \pm 5.3) \times 10^{21} \mathrm{~m}^{-3}\left(800{ }^{\circ} \mathrm{C}\right)$ and $(5.6 \pm 0.6) \times 10^{21} \mathrm{~m}^{-3}\left(1000{ }^{\circ} \mathrm{C}\right)$, whereas the average void sizes are $5.7 \pm 0.6 \mathrm{~nm}\left(800{ }^{\circ} \mathrm{C}\right)$ and $7.1 \pm 1.3 \mathrm{~nm}\left(1000^{\circ} \mathrm{C}\right)$. In contrast, radiation-induced voids were not detected in the $\mathrm{W}-5 \mathrm{Ta}$ sample irradiated at $800{ }^{\circ} \mathrm{C}$ up to $0.3 \mathrm{dpa}$. Interestingly, voids are visible when the same sample is post-irradiation annealed at $1000{ }^{\circ} \mathrm{C}$, with a void density of $4.9 \pm 1.4 \times 10^{21}$ $\mathrm{m}^{-3}$ and an average size of $4.9 \pm 1.4 \mathrm{~nm}$. This results from void agglomeration by a thermally activated process. Furthermore, the presence of $5 \mathrm{wt} . \%$ Ta causes a significant increase in void density at $1000{ }^{\circ} \mathrm{C}$ as compared to the $\mathrm{W}$ sample irradiated at that temperature, from $5.6 \pm 0.6 \times 10^{21} \mathrm{~m}^{-3}(\mathrm{~W})$ to $45.5 \pm 4.6 \times 10^{21} \mathrm{~m}^{-3}(\mathrm{~W}-5 \mathrm{Ta})$ at $0.4 \mathrm{dpa}$. The average void size is comparable for both samples at $1000{ }^{\circ} \mathrm{C}$ and 0.4 dpa, namely $7.4 \pm 0.9 \mathrm{~nm}(\mathrm{~W})$ and $7.1 \pm 1.3$ $\mathrm{nm}(\mathrm{W}-5 \mathrm{Ta})$. However, the void size seems to gradually saturate at damage levels $\geq 0.2 \mathrm{dpa}$ in $\mathrm{W}-5 \mathrm{Ta}$, whereas it increases at a constant rate in W. Additionally, in both materials the voids 
present in the microstructure gradually change their shape from spherical to either quadrilateral and/or hexagonal projections at $\geq 0.3$ dpa at both irradiation temperatures - see insets in Fig. $2 \& 3$ and also Fig. 5. The size of the voids did not surpass $8 \mathrm{~nm}$ in either material, see Fig. 4.

\section{Discussion}

The irradiated microstructure at both 800 and $1000{ }^{\circ} \mathrm{C}$ is characterised by the presence of a relatively large number of voids, whose density and average size changes with damage level, irradiation temperature and Ta content. The radiation-induced voids seem, in general, to be uniformly and randomly distributed inside the matrix grains. However, we have also detected in some cases a fine denuded zone close to grain boundaries (see Fig. 2), and also a number of voids aligned along a pre-existing dislocation line in the material (e.g. see 0.1 dpa in Fig. 3). Grain boundaries tend to act as effective non-saturable sinks for radiation-induced point defects, leading to a local zone depleted of point defects that reduces markedly the nucleation and growth rate of vacancy clusters and voids [53, 54]. The $a_{0} / 2<111>\{1-10\}$ edge dislocation-vacancy interaction in bcc metals is positive for vacancy locations above and below the dislocation slip plane [55]; the dislocation therefore assisting in the nucleation of voids in its vicinity. However, we have not detected the presence of radiation-induced dislocation loops at 800 or $1000{ }^{\circ} \mathrm{C}$. At those elevated temperatures, interstitial dislocation loops would be unstable and emit self-interstitial atoms, or glide to the free sample surface [41]. The vacancy-type loops that would have formed at temperatures $>600{ }^{\circ} \mathrm{C}$, would transit into a more stable void configuration at temperatures close to $1000{ }^{\circ} \mathrm{C}$ [41]. Once reached a critical size, voids would continue growing by absorbing additional mobile vacancies from the matrix [56].

The population of voids present in irradiated $\mathrm{W}$ decreases in density when increasing the irradiation temperature from 800 to $1000{ }^{\circ} \mathrm{C}$, whereas the average void size increases, in 
agreement with previous work on neutron irradiated $\mathrm{W}$ samples to $\sim 9.5 \mathrm{dpa}$ that present a void swelling peak at $0.31 T_{m}=1060{ }^{\circ} \mathrm{C}[20,44]$. At damage levels $\geq 0.2 \mathrm{dpa}$, soft impingement starts to occur, so that voids have an enhanced probability of growing by absorption of free vacancies or void coalescence, as compared to the nucleation of additional voids. In contrast, the presence of $5 \mathrm{wt} . \% \mathrm{Ta}$ in solid solution precludes the formation of voids at $800{ }^{\circ} \mathrm{C}$ up to a damage level of $0.3 \mathrm{dpa}$. However, a significant excess of radiation-induced vacancies does exist in the microstructure, so that voids are detected when post-irradiation annealing the sample at $1000{ }^{\circ} \mathrm{C}$ for $15 \mathrm{~min}$. First-principle calculations revealed that the Ta solute-vacancy interaction is attractive, with a binding energy of -0.1 to $-0.3 \mathrm{eV}$ for the firstto-third nearest-neighbour positions [57]. This can be ascribed to the combination of, and competition between, electronic and strain-relief effects $[57,58]$. The consequence is an effective vacancy trap nearby oversized Ta solute atoms [58], which leads to the hindrance at $800{ }^{\circ} \mathrm{C}$ of vacancy migration and void formation. Moreover, the average void size seems to gradually saturate at damage levels $>0.2 \mathrm{dpa}$ at the higher irradiation temperature of $1000{ }^{\circ} \mathrm{C}$. At $\geq 0.3 \mathrm{dpa}$, the voids present in both materials transit steadily from spherical to faceted shapes, as dictated by the anisotropy of the surface energy and by the preferential absorption of diffusing vacancies on specific plane orientations with respect to the void surface [59]. At $1000{ }^{\circ} \mathrm{C}$ and $0.4 \mathrm{dpa}$, the number fraction of faceted voids amounts to $30 \%$ in $\mathrm{W}$ and only $12 \%$ in W-5Ta.

\section{Conclusions}

The in-situ TEM study of the microstructure evolution of $\mathrm{W}$ material proton-irradiated, step-wise up to an accumulated damage level of $0.4 \mathrm{dpa}$, revealed the presence of a population of voids that are in general randomly and uniformly distributed inside the grains of the matrix. An increase in irradiation temperature from 800 to $1000{ }^{\circ} \mathrm{C}$ causes a significant decrease in void density, and concomitantly an increase in average void size. Soft 
impingement seems to take place at $\geq 0.2$ dpa where the void size experiences a more rapid increase with the damage level. The presence of only $5 \mathrm{wt} . \% \mathrm{Ta}$ in solid solution hinders the diffusion of free radiation-induced vacancies at $800{ }^{\circ} \mathrm{C}$, and consequently precludes the formation of voids up to $0.3 \mathrm{dpa}$. Moreover, solute Ta atoms also induce a remarkable increase in void density at $1000{ }^{\circ} \mathrm{C}$ as compared to $\mathrm{W}$ under equivalent irradiation conditions, and a gradual progression in average void size towards saturation at $\geq 0.2 \mathrm{dpa}$. Furthermore, a significant number of voids in both materials, initially formed as spherical embryos, experience a progressive transition to a faceted shape at $\geq 0.3 \mathrm{dpa}$.

\section{Acknowledgments}

The authors of this work acknowledge access to the MIAMI-II facility through the EPSRC-funded mid-range facility, the UK National Ion Beam Centre (NS/A000059/1). In addition, access to sample preparation equipment provided by the Dalton Cumbrian Facility of The University of Manchester is acknowledged. Authors I.I., M.J.D.R. and S.C.M. are supported through the Sêr Cymru Nuclear Futures Institute funded through WEFO (Wales). We would particularly like to thank Prof. W.E. Lee for his support and guidance.

\section{References}

[1] D. Hancock, D. Homfray, M. Porton, I. Todd, B. Wynne, Refractory metals as structural materials for fusion high heat flux components. J. Nucl. Mater. 512 (2018) 169-183.

[2] T. Hirai, S. Panayotis, V. Barabash, C. Amzallag, F. Escourbiac, A. Durocher et al., Use of tungsten material for the ITER divertor. Nucl. Mater. Energy 9 (2016) 616-22.

[3] M. Rieth, S.L. Dudarev, S.M. Gonzalez de Vicente, J. Aktaa, T. Ahlgren, S. Antusch, et al., Recent progress in research on tungsten materials for nuclear fusion applications in Europe. J. Nucl. Mater. 432 (2013) 482-500. 
[4] S.J. Zinkle, A. Mösslang, T. Muroga, H. Tanigawa, Multimodal options for materials research to advance the basis for fusion energy in the ITER era. Nucl. Fusion 53 (2013) 104024 (13pp).

[5] R.G. Abernethy, Predicting the performance of tungsten in a fusion environment: a literature review, Mater. Sci. Technol. 33 (2017) 388.

[6] C. Thomser, V. Bailescu, S. Brezinsek, J.W. Coenen, H. Greuner, T. Hirai et al., Plasma Facing Materials for the JET ITER-Like Wall. Fusion Sci. Technol. 62 (2012) 1-8.

[7] A. Widdowson, E. Alves, A. Baron-Wiechec, N.P. Barradas, N. Catarino, J.P. Coad et al., Overview of the JET ITER-like wall divertor. Nucl. Mater. Energy 12 (2017) 499-505.

[8] R. Villari, V. Barabash, F. Escourbiac, L. Ferrand, T. Hirai, V. Komarov et al., Nuclear analysis of the ITER full-tungsten divertor. Fusion Eng. Des. 88 (2013) 2006-10.

[9] S.Heuer, Th.Weber, G.Pintsuk, J.W.Coenen, J.Matejicek, Ch.Linsmeier, Aiming at understanding thermo-mechanical loads in the first wall of DEMO: Stress-strain evolution in a Eurofer-tungsten test component featuring a functionally graded interlayer. Fus. Eng. Design 135 (2018) 141-153.

[10] A. Li-Puma, M. Richou, P. Magaud, M. Missirlian, E. Visca, V.P. Ridolfini, Potential and limits of water cooled divertor concepts based on monoblock design as possible candidates for a DEMO reactor. Fusion Eng. Des. 88 (2013) 1836-1843.

[11] S.J. Zinkle, N.M. Ghoniem, Operating temperature windows for fusion reactor structural materials. Fusion Eng. Des. 51-52 (2000) 55-71.

[12] T. Shen,Y. Dai,Y. Lee, Microstructure and tensile properties of tungsten at elevated temperatures. J. Nucl. Mater. 468 (2016) 348-354.

[13] P. Gumbsch. Brittle fracture and the brittle-to-ductile transition of tungsten, J. Nucl. Mater. 323 (2003) 304-312. 
[14] B.Gludovatz, S.Wurster, A.Hoffmann, R.Pippan, Fracture toughness of polycrystalline tungsten alloys. Int. J. Refract. Met. Hard Mater. 28 (2010) 674-678.

[15] E. Gaganidze, D. Rupp, J. Aktaa, Fracture behaviour of polycrystalline tungsten. J. Nucl. Mater. 446 (2014) 240-245.

[16] H. Bolt, V. Barabash, G. Federici, J. Linke, A. Loarte, J. Roth, K. Sato, Plasma facing and high heat flux materials - needs for ITER and beyond. J. Nucl. Mater. 307-311 (2002) 43-52.

[17] I.V. Gorynin, V.A. Ignatov, V.V. Rybin, S.A. Fabritsiev, V.A. Kazakov, V.P. Chakin, et al., Effects of neutron irradiation on properties of refractory metals. J. Nucl. Mater. 191-194 (1992) 421-425.

[18] L.K. Keys, J.P. Smith, J. Moteff, Stage III recovery in neutron irradiated tungsten. Scripta Metall. 1 (1967) 71-72.

[19] V.K. Sikka, J. Moteff, "Rafting" in neutron irradiated tungsten. J. Nucl. Mater. 46 (1973) 217-219.

[20] T. Koyanagi, N.A.P. Kiran Kumar, T. Hwang, L.M. Garrison, X. Hu, L.L. Snead, Y. Katoh, Microstructural evolution of pure tungsten neutron irradiated with a mixed energy spectrum. J. Nucl. Mater. 490 (2017) 66-74.

[21] J.M. Galligan, T. Oku, Dislocation Loops in Neutron Irradiated Tungsten. Phys. Stat. Sol. 36 (1969) K79-K82.

[22] T. Koyagani, N.A.P. Kiran Kumar, T. Hwang, L.M. Garrison, X. Hu, L.L. Snead, Y. Katoh. Microstructural evolution of pure tungsten neutron irradiated with a mixed energy spectrum. J. Nucl. Mater. 490 (2017) 66-74.

[23] X. Hu, T. Koyanagi, M. Fukuda, N.P.P. Kiran Kumar, L.L. Snead, B.D. Wirth, Y. Katoh, Irradiation hardening of pure tungsten exposed to neutron irradiation. J. Nucl. Mater. 480 (2016) 235-243. 
[24] X. Hu, C.M. Parish, K. Wang, T. Koyamagi, B.P. Eftink, Y. Katoh, Transmutationinduced precipitation in tungsten irradiated with a mixed energy spectrum. Acta Mater. 165 (2019) 51-61.

[25] R.W. Harrison, On the use of ion beams to emulate the neutron irradiation behaviour of tungsten. Vacuum 160 (2019) 355-370.

[26] X. Yi, M.L. Jenkins, M. Briceno, S.G. Roberts, Z. Zhou, M.A. Kirk, In-situ study of self-ion irradiation damage in $\mathrm{W}$ and W-5Re at $500^{\circ} \mathrm{C}$. Phil. Mag. 93 (2013) 1715-1738.

[27] F. Ferroni, X. Yi, K. Arakawa, S.P. Fitzgerald, P.D. Edmonson, S.G. Roberts, High temperature annealing of ion irradiated tungsten. Acta Mater. 90 (2015) 380-393.

[28] M. Rieth, S.L. Dudarev, S.M. Gonzalez de Vicente, J.Aktaa, T.Ahlgren, S.Antusch, et al., A brief summary of the progress on the EFDA tungsten materials program. J. Nucl. Mater. 442 (2013) S173-S180.

[29] D. Jiang, Q. Wang, W. Hu, Z. Wei, J. Tong, H. Wan, The effect of tantalum (Ta) doping on mechanical properties of tungsten (W): A first-principles study. J. Mater. Res. 31 (2016) $3401-3408$.

[30] Z. Wang, Y. Yuan, K. Arshad, J. Wang, Z. Zhou, J. Tang, G.-H. Lu, Effects of tantalum concentration on the microstructures and mechanical properties of tungsten-tantalum alloys. Fusion Eng. Des. 125 (2017) 496-502.

[31] P.E.A. Turchi, A. Gonis, V. Drchal, J. Kudmonvský, First-principles study of stability and local order in substitutional Ta-W alloys. Phys. Rev. B 64 (2001) 085112 (8pp).

[32] D.E.J. Armstrong, A.J. Wilkinson, S.G. Roberts, Mechanical properties of ion-implanted tungsten-5wt,\% tantalum. Phys. Scr. T145 (2011) 014076 (4pp).

[33] X. Yi, M.L. Jenkins, K. Hattar, P.D. Edmondson, S.G. Roberts, Characterisation of radiation damage in $\mathrm{W}$ and $\mathrm{W}$-based alloys from $2 \mathrm{MeV}$ self-ion near-bulk implantations. Acta Mater. 92 (2015) 163-177. 
[34] A. Xu, D.E.J. Armstrong, C. Beck, M.P. Moody, G.D.W. Smith, P.A.J. Bagot et al., Ionirradiation induced clustering in W-Re-Ta, W-Re and W-Ta alloys: An atom probe tomography and nanoindentation study. Acta Mater. 124 (2017) 71-78.

[35] I. Ipatova, R.W. Harrison, P.T. Wady, S.M. Shubeita, D. Terentyev, S.E. Donnelly, E. Jimenez-Melero, Structural defect accumulation in tungsten and tungsten-5wt,\% tantalum under incremental proton damage. J. Nucl. Mater. 501 (2017) 329.

[36] W. Setyawan, G. Nandipati, R.J. Kurtz, Ab initio study of interstitial cluster interaction with Re, Os, and Ta in W. J. Nucl. Mater. 484 (2017) 30-41

[37] L.K. Keys, J.Moteff, Neutron irradiation and defect recovery of tungsten. J. Nucl. Mater. 34 (1970) 260-280.

[38] Y.-W. Kim, J.M. Galligan, An annealing study of thermal neutron irradiated tungsten. J. Nucl. Mater. 69 \& 70 (1978) 680-682.

[39] D.N. Seidman, On the point-defect annealing mechanism for stage III recovery in irradiated or quenched tungsten. Scripta Metall. 13 (1979) 251-257.

[40] T. Tanno, M. Fukuda, S. Nogami, A. Hasegawa. Microstructure Development in Neutron Irradiated Tungsten Alloys. Mater. Trans. 52 (2011) 1447-1451.

[41] I. Ipatova, R.W. Harrison, D. Terentyev, S.E. Donnelly, E. Jimenez-Melero, Thermal evolution of the proton irradiated structure in tungsten-5wt\% tantalum, J. Fusion Energy 36 (2017) 234-239.

[42] X. Yi, K. Arakawa, Y. Du, F. Ferroni, W. Han, P. Liu, F. Wan, High-temperature defect recovery in self-ion irradiated W-5 wt\% Ta. Nucl. Mater. Energy 18 (2019) 93-98.

[43] M.R. Gilbert, S.L. Dudarev, P.M. Derlet, D.G. Pettifor, Structure and metastability of mesoscopic vacancy and interstitial loop defects in iron and tungsten. J. Phys.: Condens. Matter 20 (2008) 345214 (10pp). 
[44] J. Matolich H. Nahm, J. Moteff, Swelling in neutron irradiated tungsten and tungsten25 percent rhenium. Scripta Metall. 8 (1974) 837-841.

[45] V.K. Sikka, J. Moteff, Superlattice of voids in neutron-irradiated tungsten. J. Appl. Phys. 43 (1972) 4942-4944.

[46] J. Linke, T. Loewenhoff, V. Massaut, G. Pintsuk, G. Ritz, M. R€odig, A. Schmidt, C. Thomser, I. Uytdenhouwen, V. Vasechko, M. Wirtz, Performance of different tungsten grades under transient thermal loads. Nucl. Fusion 51 (2011) 073017.

[47] Y. Zayachuk, M.H.J. t Hoen, P.A. Zeijlmans van Emmichoven, D. Terentyev, I. Uytdenhouwen, G. van Oost, Nucl., Surface modification of tungsten and tungsten-tantalum alloys exposed to high-flux deuterium plasma and its impact on deuterium retention. Fusion $53(2013) 013013$.

[48] J.A. Hinks, J.A. van den Berg, S.E. Donnelly. MIAMI: Microscope and ion accelerator for materials investigations. J. Vac. Sci. Technol. A-Vac. Surf. Films 29 (2011) 021003 (6pp).

[49] J.F. Ziegler, Stopping of energetic light ions in elemental matter. J. Appl. Phys. 85 (1999) 1249-1272.

[50] J.F. Ziegler, M.D. Ziegler, J.P. Biersack, SRIM - The stopping and range of ions in matter (2010). Nucl. Instrum. Meth. Phys. Res. B 268 (2010) 1818-1823.

[51] ASTM E521-96, Standard Practice for Neutron Radiation Damage Simulation by Charged-particle Irradiation, 2009.

[52] M.L. Jenkins, M.A. Kirk, Characterization of Radiation Damage by Transmission Electron Microscopy, IOP Publishing Ltd, 2001.

[53] B.N. Singh, On the influence of grain boundaries on void growth. Phil. Mag. 28 (1973) 1409-1413. 
[54] D.I.R. Norris, The use of the high voltage electron microscope to simulate fast neutroninduced void swelling in metals. J. Nucl. Mater. 40 (1971) 66.

[55] K.W. Ingle, A.G. Crocker, The interaction between vacancies and $\frac{1}{2}<111>\{1-10\}$ edge dislocation in body centred cubic metals. Acta Metall. 26 (1978) 1461-1469.

[56] B.L. Eyre, D.M. Maher, Neutron irradiation damage in molybdenum. Philos. Mag. 24 (1971) 767-797.

[57] X.-S. Kong, X. Wu, Y.-W. You, C.S. Liu, Q.F. Fang, J.-L. Chen et al., First-principles calculations of transition metal-solute interactions with point defects in tungsten. Acta Mater. 66 (2014) 172-183.

[58] F.A. Smidt Jr., J.A. Sprague, Suppression of void nucleation by a vacancy trapping mechanism. Scripta Metall. 7 (1973) 495-501.

[59] W.B. Liu, N. Wang, Y.Z. Ji, P.C. Song, C. Zhang, Z.G. Yang et al., Effects of surface energy anisotropy on void evolution during irradiation: A phase-field model. J. Nucl. Mater. 479 (2016) 316-322.

\section{Tables}

Table 1. The main experimental parameters that characterise the in-situ proton irradiation of W and W-5Ta materials at $800{ }^{\circ} \mathrm{C}$ and $1000{ }^{\circ} \mathrm{C}$. The samples were studied in-situ by TEM at selected incremental damage levels. The fluence given in the table refers to the total value achieved at the end of the irradiation. The damage level corresponds to the average value over the disc thickness of $\sim 100-110 \mathrm{~nm}$ studied by in-situ TEM.

Table 2. The main parameters that characterise the population of radiation-induced voids observed in W and W-5Ta materials at selected damage levels. 


\section{Figure captions}

Fig. 1. Electron Backscattered Diffraction maps of the $\mathrm{W}$ and $\mathrm{W}-5 \mathrm{Ta}$ microstructures prior to proton irradiation (taken from [35]).

Fig. 2. In-situ observation of void growth, together with changes in void shape (insets), in W under increasing damage levels induced by a $40 \mathrm{keV}$ proton beam at $800{ }^{\circ} \mathrm{C}$ and $1000^{\circ} \mathrm{C}$. Yellow dotted line denotes denuded zone.

Fig. 3. In-situ observation of void growth, together with changes in void shape (insets) in W-5Ta material under increasing damage levels induced by $40 \mathrm{keV}$ proton bombardment at $1000^{\circ} \mathrm{C}$. Radiation-induced voids were not detected in the irradiated material at $800{ }^{\circ} \mathrm{C}$, but can be seen in the same sample after post-irradiation annealing at $1000{ }^{\circ} \mathrm{C}$.

Fig. 4. Average size and number-density of voids in $\mathrm{W}$ and $\mathrm{W}-5 \mathrm{Ta}$ alloy as a function of damage level, at the irradiation temperature of either 800 or $1000{ }^{\circ} \mathrm{C}$. Voids were not detected in the W-5Ta proton irradiated up to a damage level of $0.3 \mathrm{dpa}$ at $800{ }^{\circ} \mathrm{C}$.

Fig. 5. Void agglomeration and change in void shape in W-5Ta at selected damage levels, induced by $40 \mathrm{keV}$ proton bombardment at $1000^{\circ} \mathrm{C}$. 


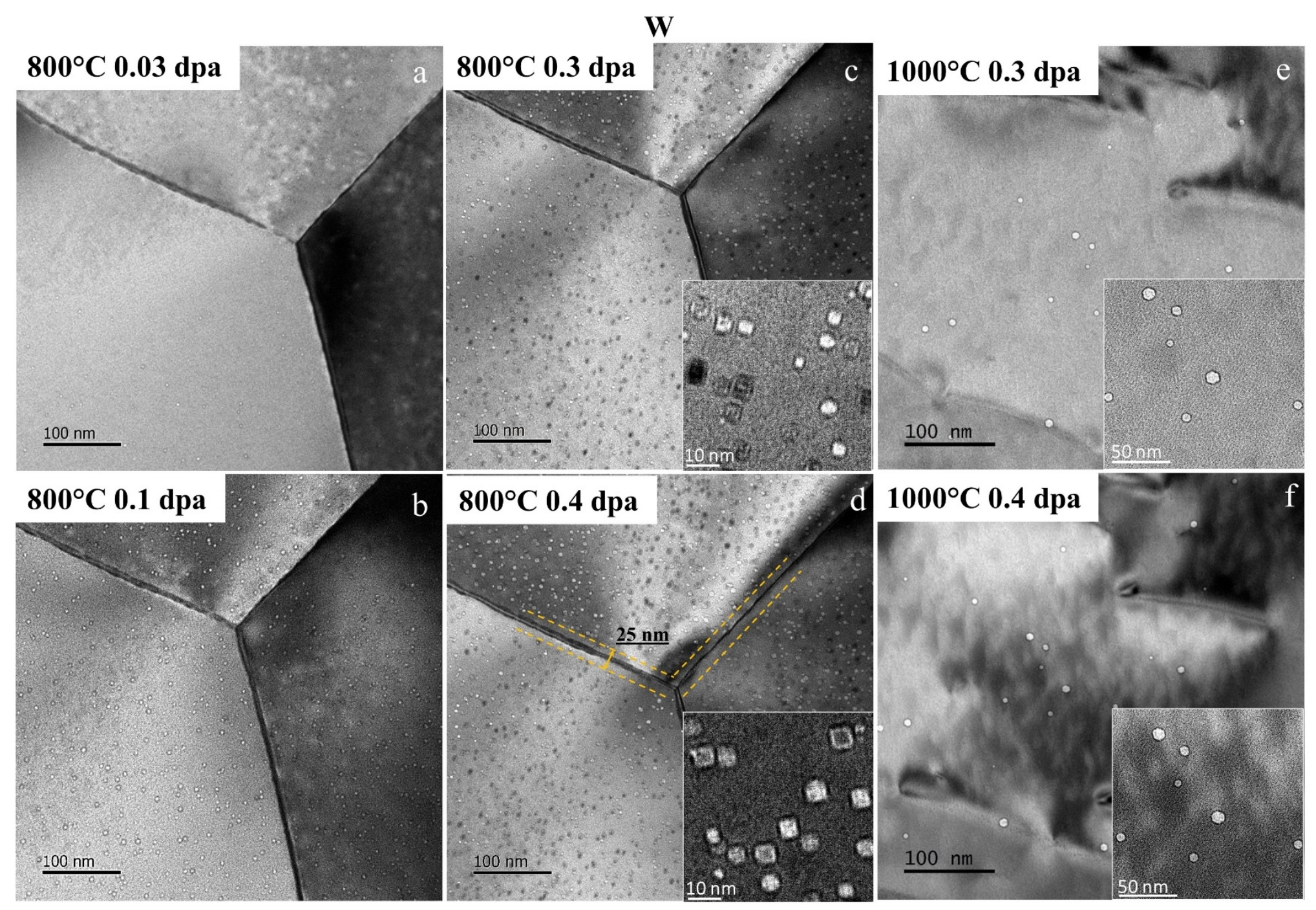

Fig. 1. In-situ observation of void growth, together with changes in void shape (insets), in W under increasing damage levels induced by a $40 \mathrm{keV}$ proton beam at $800{ }^{\circ} \mathrm{C}$ : (a) $0.03 \mathrm{dpa}$, (b) $0.1 \mathrm{dpa}$, (c) $0.3 \mathrm{dpa}$, (d) $0.4 \mathrm{dpa}$; and $1000^{\circ} \mathrm{C}$ : (e) $0.3 \mathrm{dpa}$, (f) $0.4 \mathrm{dpa}$. Yellow dotted line denotes denuded zone. 


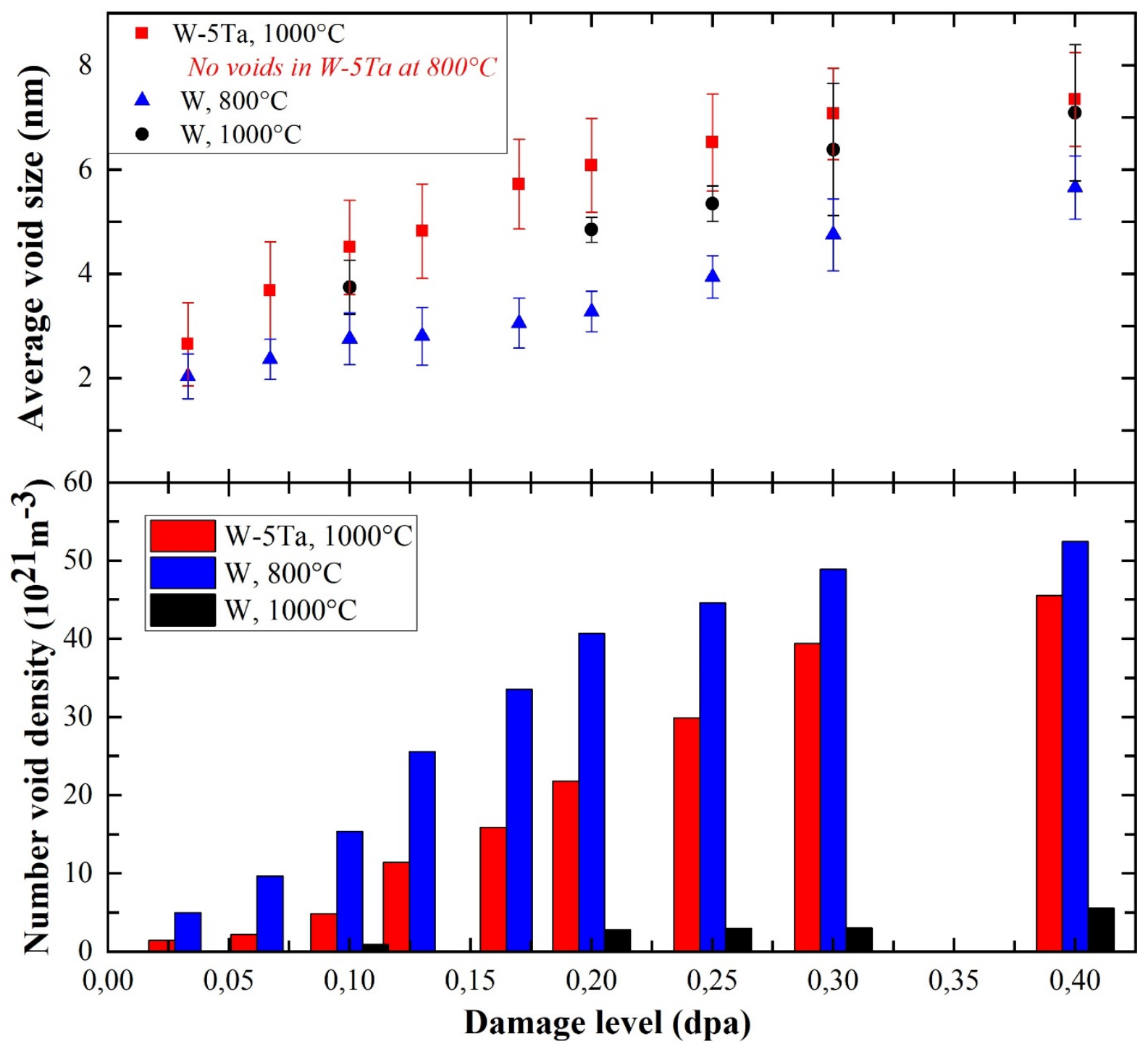

Fig. 3. Average size and number-density of voids in $\mathbf{W}$ and $\mathbf{W}-\mathbf{5 T a}$ alloy as a function of damage level, at the irradiation temperature of either 800 or $1000^{\circ} \mathrm{C}$. Voids were not detected in the W-5Ta proton irradiated up to a damage level of $0.3 \mathrm{dpa}$ at $800{ }^{\circ} \mathrm{C}$. 

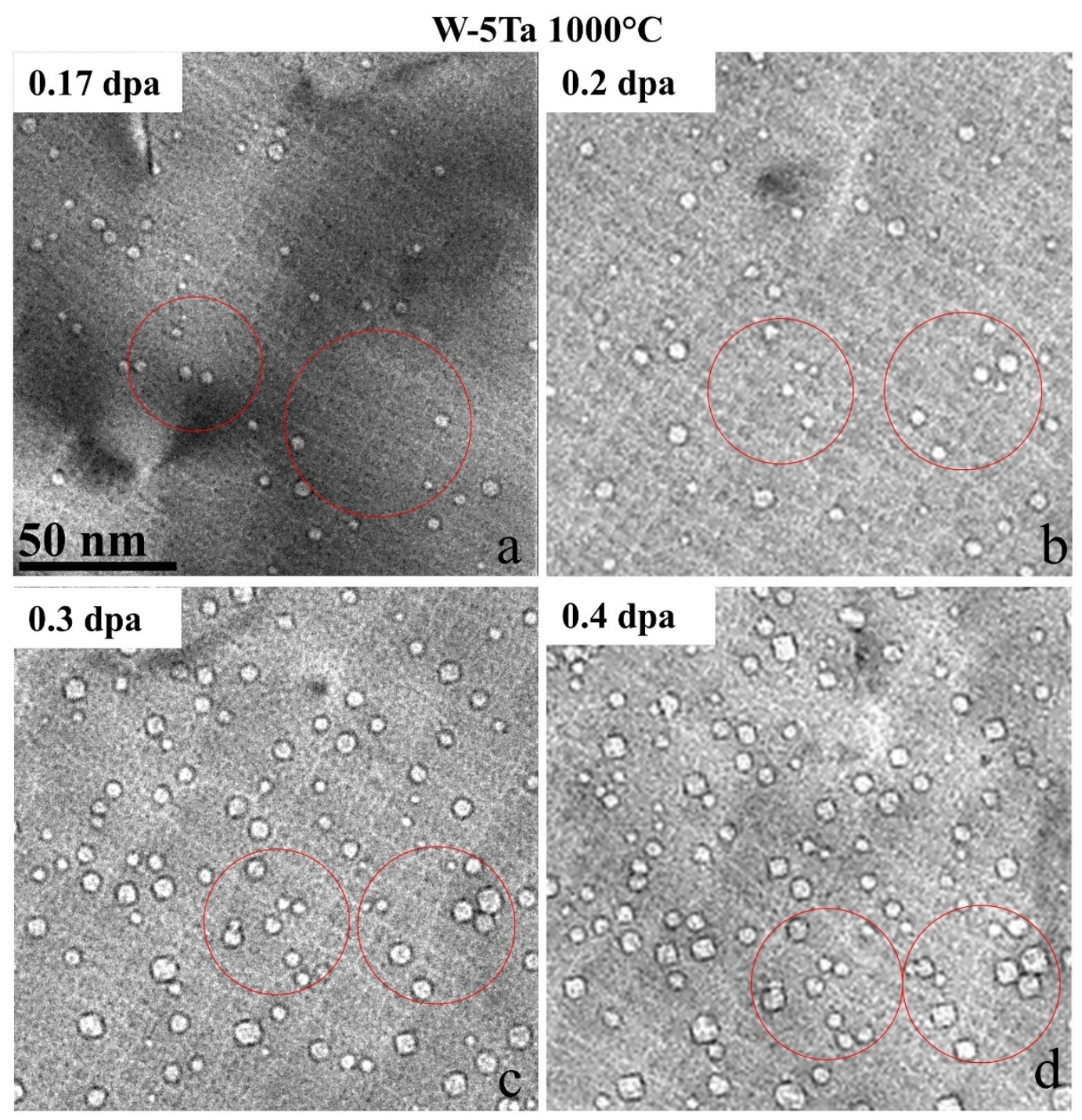

Fig. 4. Void agglomeration and change in void shape in W-5Ta at selected damage levels, induced by $40 \mathrm{keV}$ proton bombardment at $1000^{\circ} \mathrm{C}$ : (a) $0.17 \mathrm{dpa}$, (b) $0.2 \mathrm{dpa}$, (c) $0.3 \mathrm{dpa}$, (d) 0.4 dpa. 

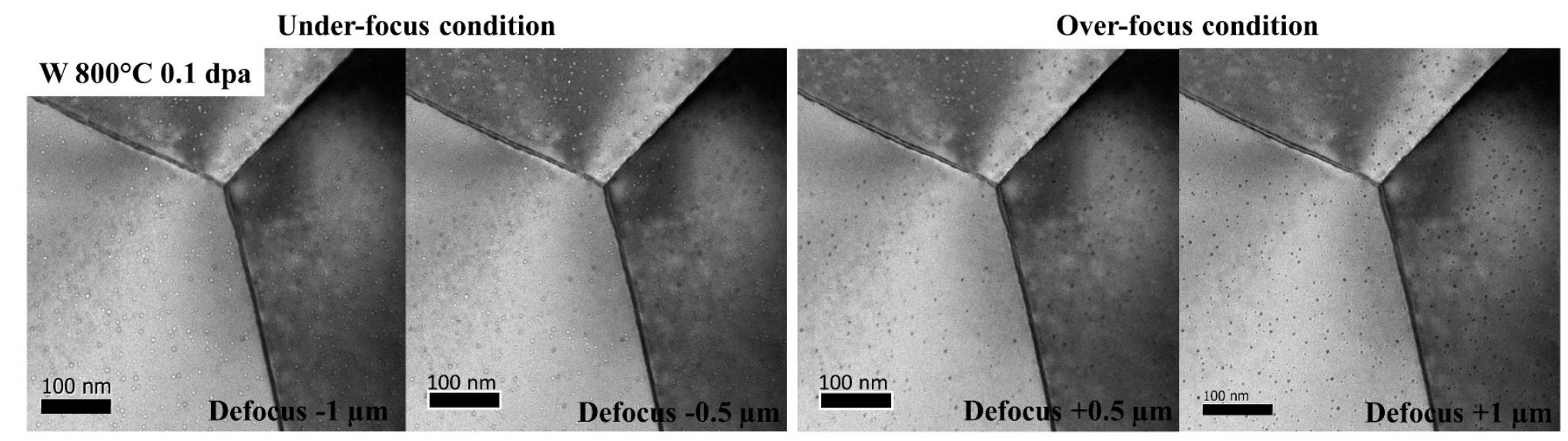

Fig. S1. Bright field TEM imaging of radiation-induced voids in $\mathbf{W}$ at the temperature of $800{ }^{\circ} \mathrm{C}$ and the damage level of $0.1 \mathrm{dpa}$, based on the out-of-focus imaging technique with selected defocus values up to $+/-1 \mu \mathrm{m}$. 


\section{Under focus}

\section{Over focus}

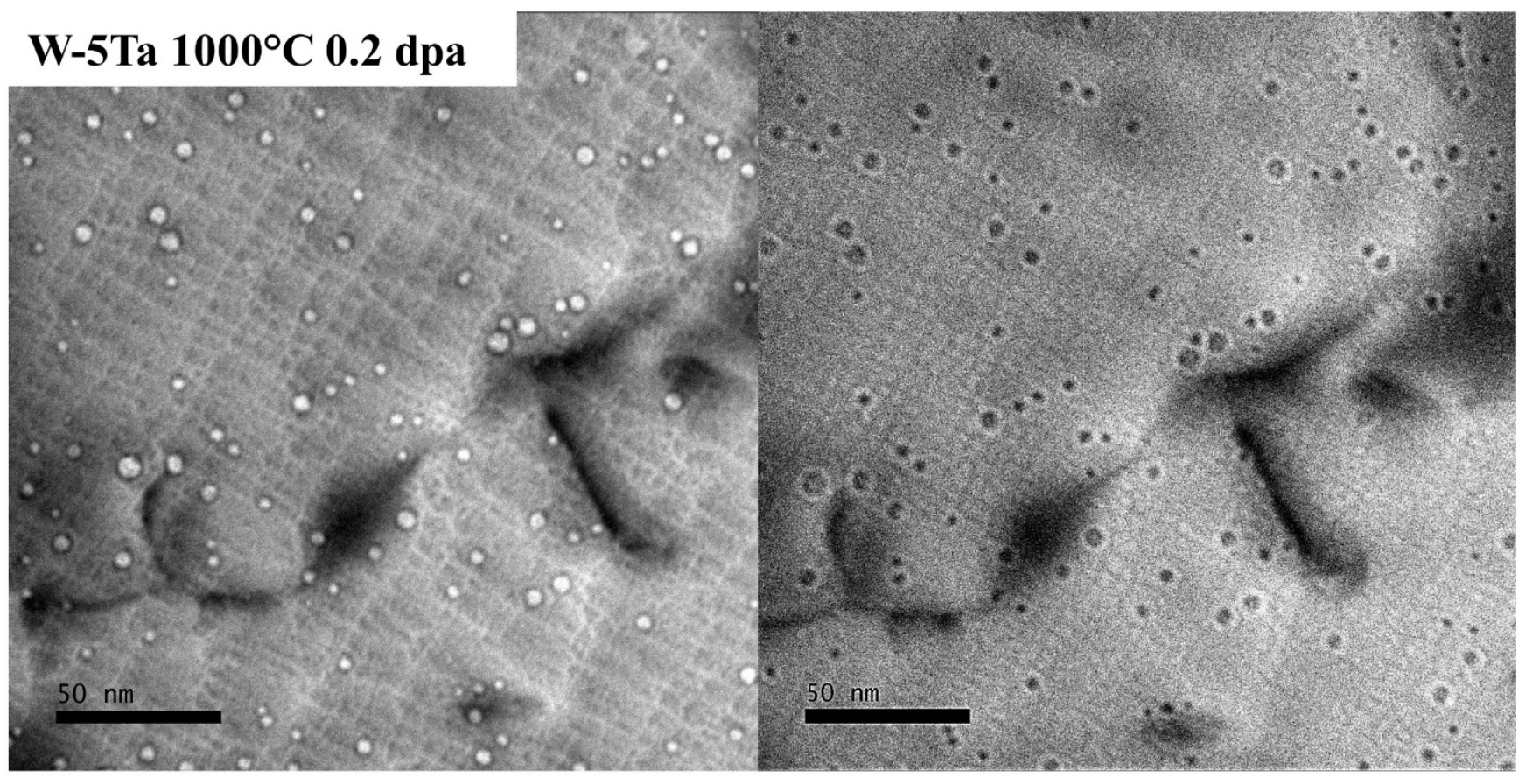

Fig. S2. Bright field TEM images of voids in W-5Ta proton-irradiated at $1000^{\circ} \mathrm{C}$ and to a damage level of at $0.2 \mathrm{dpa}$. The images were taken using the out-of-focus imaging technique with the defocus value of $+/-500 \mathrm{~nm}$. Dislocations present in the micrographs correspond to pre-existing dislocations prior to irradiation. 
Table 1

\begin{tabular}{|l|c|c|c|c|}
\hline Temperature $\left({ }^{\circ} \mathrm{C}\right)$ & \multicolumn{2}{|c|}{$\mathbf{8 0 0}^{\circ} \mathrm{C}$} & \multicolumn{2}{c|}{$\mathbf{1 0 0 0}^{\circ} \mathrm{C}$} \\
\hline Material & W & W-Ta & W & W-Ta \\
\hline Proton energy & \multicolumn{4}{|c|}{$40 \mathrm{keV}$} \\
\hline Current (nA) & 0.29 & 0.15 & 0.17 & 0.2 \\
\hline Fluence (ions/cm ${ }^{2}$ ) & $7.66 \times 10^{17}$ & $4.7 \times 10^{17}$ & $7.66 \times 10^{17}$ & $6.3 \times 10^{17}$ \\
\hline Flux (ions/cm $/ \mathrm{s})$ & $1.15 \times 10^{14}$ & $6 \times 10^{13}$ & $6.8 \times 10^{13}$ & $8 \times 10^{13}$ \\
\hline Damage rate (dpa/s) & $7.3 \times 10^{-5}$ & $3.8 \times 10^{-5}$ & $4.3 \times 10^{-5}$ & $5.05 \times 10^{-5}$ \\
\hline Damage level (dpa) & 0.5 & 0.3 & 0.5 & 0.4 \\
\hline
\end{tabular}


Table 2

\begin{tabular}{|c|c|c|c|c|c|}
\hline Material & $\begin{array}{c}\text { Temperature, } \\
{ }^{\circ} \mathrm{C}\end{array}$ & $\begin{array}{c}\text { Damage } \\
\text { level, } \\
\text { dpa }\end{array}$ & $\begin{array}{c}\text { Average void } \\
\text { size, } \mathrm{nm}\end{array}$ & $\begin{array}{c}\text { Void } \\
\text { density, } \\
10^{21} \mathrm{~m}^{-3}\end{array}$ & $\begin{array}{c}\text { Fraction of } \\
\text { squared voids at } \\
0.4 \mathrm{dpa}^{*}, \%\end{array}$ \\
\hline \multirow{4}{*}{$\mathbf{W}$} & \multirow{2}{*}{$800^{\circ} \mathrm{C}$} & 0.2 & $3.3 \pm 0.4$ & $40.7 \pm 4.1$ & \\
\hline & & 0.4 & $5.7 \pm 0.6$ & $52.5 \pm 5.3$ & \\
\hline & \multirow{2}{*}{$1000^{\circ} \mathrm{C}$} & 0.2 & $4.9 \pm 0.3$ & $2.8 \pm 0.3$ & \\
\hline & & 0.4 & $7.1 \pm 1.3$ & $5.6 \pm 0.6$ & 30 \\
\hline \multirow{4}{*}{ W-5Ta } & $800^{\circ} \mathrm{C}$ & \multicolumn{4}{|c|}{ No voids observed } \\
\hline & $\begin{array}{l}\text { Annealed at } \\
1000^{\circ} \mathrm{C}\end{array}$ & after 0.3 & $4.86 \pm 1.4$ & $1.4 \pm 0.1$ & \\
\hline & \multirow{2}{*}{$1000^{\circ} \mathrm{C}$} & 0.2 & $6.1 \pm 0.9$ & $21.8 \pm 2.2$ & \\
\hline & & 0.4 & $7.4 \pm 0.9$ & $45.5 \pm 4.6$ & 12 \\
\hline
\end{tabular}

* The fraction of square voids was calculated at the maximum damage level $(0.4 \mathrm{dpa})$ for $\mathrm{W}$ sample irradiated at $800^{\circ} \mathrm{C}$ and W-5Ta sample irradiated at $1000^{\circ} \mathrm{C}$ due to the highest density of the voids. 